\title{
EL PLAGIO. ESPECIAL REFERENCIA A LA OBRA CINEMATOGRÁFICA
}

El objeto de protección del derecho de autor es la obra, entendida como aquella manifestación de ingenio de su autor o creador de naturaleza literaria o artística, dotada del requisito esencial de la originalidad y presentada al mundo exterior a través de cualquier medio o soporte apto para tal finalidad. Así, dentro del concepto general de obra se encuentran las obras cinematográficas, especie de la obra audiovisual dirigida exclusivamente al sector del cine y conocida popularmente como película o filme, independientemente del género, de su duración, destino, etc.

Este tipo de obras son unas de las creaciones con más impacto a nivel cultural y social ya que tienen la capacidad de entretener al público con sus diversos géneros (romántico, dramático, terror, etc.), o por el contrario, de generar en el espectador una visión crítica respecto de alguna situación o pensamiento, la consideración de la dicotomía del bien y el mal, o el cuestionamiento respecto de normas socialmente establecidas, deviniendo incluso muchas de ellas producciones de culto, esto en razón de los elementos visuales empleados, el desarrollo del guion, la caracterización de personajes, la escenografía, etc. A nivel económico, pueden llegar a influir directamente en el PIB de un país ${ }^{1}$, por cuanto representan a una de las más fuertes industrias en el mundo del entretenimiento.

\footnotetext{
* Abogada de la Universidad Externado de Colombia y magíster en Derecho con énfasis en Propiedad Intelectual de la misma Universidad. Contacto: dianacarolina.baezjimenez@ gmail.com
}

Fecha de recepción: 14 de abril de 2015. Fecha de aceptación: 2 de mayo de 2015. Para citar el artículo: Báez Jiménez, D. C. El plagio. Especial referencia a la obra cinematográfica. Revista La Propiedad Inmaterial n. ${ }^{\circ}$ 19, Universidad Externado de Colombia, enero-junio, 2015, pp. 113-166. DOI: 10.18601/16571959.n19.06

1. Cordy Castañeda, Alberto, lópez Cubillos, Rafael, lópez Sarmiento, Armando y Gordillo Vallecilla, Jaime. La contribución económica de las industrias del Derecho de Autor y los Derechos Conexos en Colombia. ompi, Bogotá, 2008. Disponible en: http:// derechodeautor.gov.co/documents/10181/46348/Estudio+Ompi+Colombia.pdf/27f06d227c6b-461c-919d-9859cfddb930 Consultado el 6 de mayo de 2015; Ministerio de Cultu- 
A nivel jurídico, y dada la importancia de las obras cinematográficas, la legislación nacional las regula de manera específica respecto de otras creaciones y les da el trato de obra compleja, por cuanto están estructuradas mediante un conjunto de múltiples obras: musicales, literarias (libretos), artísticas (fotografía), etc. Asimismo, confluyen en ella sus múltiples autores, tanto personas naturales como personas jurídicas que detentan los derechos morales y patrimoniales, como el director, el autor del guion, el autor de la música, el productor cinematográfico, entre otros.

De esta manera y al tener un poder innegable en los ámbitos mencionados, despiertan interés en aquellos individuos que buscan sacar provecho de la creación original de otros, haciendo pasar como suyos y apropiándose indebidamente de elementos protegidos de una obra cinematográfica para incorporarlos en otra carente de originalidad; de esa manera buscan obtener un reconocimiento o prestigio que en realidad no les corresponde, con independencia de si su actuar está condicionado o no por un ánimo de lucro. Dicha conducta infractora es conocida como plagio, predicable no solamente de las obras literarias, como generalmente ocurre, sino de cualquier tipo de creación.

Esta situación pone en evidencia que en la práctica las producciones cinematográficas pueden verse, al igual que cualquier otra obra, afectadas por conductas lesivas y que perjudican los derechos de sus creadores. Es por ello que países con una industria cinematográfica consolidada, como Estados Unidos, Argentina o España, entre otros, se han preocupado por realizar estudios concienzudos y especializados en esta materia, no solo produciendo doctrina al respecto, sino formulando nuevos métodos sistemáticos a nivel jurisprudencial, los cuales permiten detectar el plagio en diversos tipos de obras audiovisuales y, en especial, en lo que se refiere a creaciones cinematográficas.

En Colombia el escenario es muy distinto, ya que la jurisprudencia y la doctrina en este campo son incipientes. De ahí que haya necesidad de acudir a doctrina y jurisprudencia extranjera a la hora de adelantar un correcto estudio del plagio de la obra cinematográfica, no solamente para su entendimiento e interpretación, sino también para observar y analizar los diferentes métodos sistemáticos que se han desarrollado a nivel jurisprudencial en torno a dicha conducta en este tipo de creaciones.

Ese vacío en el ámbito del derecho de autor en nuestro país motiva un estudio sobre la figura del plagio de las obras cinematográficas, buscando obtener herramientas a nivel teórico que permitan presentar y aplicar en Colombia un

ra. Impacto económico de las industrias culturales en Colombia. Ministerio de Cultura de Colombia, Equipo Central de Economía y Cultura del Convenio Andrés Bello, Bogotá, Colombia, 2003. Disponible en: http://www.odai.org/biblioteca/biblioteca1/4.pdf Consultado el 6 de mayo de 2015. 
método estructurado en una serie de pasos que posibiliten la detección de esta conducta, proveniente tanto de los elementos literales como no literales entre obras cinematográficas, o entre estas y otras de cualquier género, para así poder fijar o delimitar la frontera entre la idea y la expresión y determinar en qué casos se ha presentado efectivamente la conducta lesiva mencionada.

\section{Concepto de plagio}

Tiene origen en la antigua palabra romana 'plagium', "derivada del griego plagios que significa dolo o fraude" 3 .

De acuerdo a la lex Fabia de plagiariis", "Se denominaba así a quien hubiera inducido a un esclavo a huir de su dueño, o dado refugio a aquél, o facilitado su fuga o cometido otros delitos congéneres que nada tiene de común con el latrocinio literario 5 . En esta legislación, de finales del período republicano romano, el 'plagium' se refería al crimen de rapto de hombres libres para reducirlos a la esclavitud, lo mismo que a la sustracción de esclavos ${ }^{6}$. Estos delitos se castigaban con la deportación a las minas o la pena de muerte"7.

Es importante resaltar que, si bien en la antigüedad no se hizo alusión expresa al derecho de autor ni hubo un desarrollo de la materia, como tampoco del plagio referido a este campo, existen referencias históricas según las cuales la realización de esta conducta traía como consecuencia un reproche social ${ }^{8}$. Sin embargo, con el paso del tiempo el concepto de plagio deja a un lado la concepción griega y

2. Della Costa, Héctor. El derecho de autor y su novedad. Estructura-dinámica-problemática, 2. ${ }^{a}$ ed., Buenos Aires, Editorial de Belgrano, 1970, p. 199: "Rapto o seducción de un esclavo, y a su vez el vocablo alude a la 'plaga', es decir a la red, lazo o trampa en que, material o figuradamente, se lo hacía caer".

3. Antequera Parilli, Ricardo. Derechos intelectuales y derecho a la imagen en la jurisprudencia comparada. Madrid, Reus, 2012, p. 83.

4. Ley publicada antes del inicio del imperio romano. Algardi, Zara Olivia. Sezione II, "Il plagio come reato e come illecito civile - Capitolo XVII: Il plagio nella coscienza giuridica e nel diritto comparato", en La tutela dell'opera dell'ingegno e il plagio. Padova, Cedam, 1978, p. 367. Traducción propia.

5. Ferrini, C. Citado por Latorre, Virgilio. Protección penal del derecho de autor. Valencia, Tirant lo Blanch, 1994, p. 175. Citado por Balbuena, Pedro Virgilio. "El plagio como ilícito penal", Revista Ventana Legal. Disponible en: http://www.ventanalegal.com/revista_ventanalegal/plagio_ilicito.htm\#_ftn4 Consultado el 6 de mayo de 2015.

6. Chaves, Antonio. "El plagio", en Memorias del I Congreso Internacional sobre la Protección de los Derechos Intelectuales (en homenaje a la memoria de Roberto Goldschmidt). Caracas, Universidad Católica "Andrés Bello", 1986, pp. 214-215. Citado por Balbuena, Pedro Virgilio. "El plagio como ilícito penal”, en Revista Ventana Legal, cit.

7. Ibíd.

8. Gutiérrez Gutiérrez, Angélica. "El plagio literario”, en Quadernos de criminología: Revista de criminología y ciencias forenses, n. ${ }^{\circ} 10$ (2010), p. 31. Disponible en: http://dialnet.unirioja.es/ Consultado el 6 de mayo de 2015. 
romana, inicialmente referida al secuestro de personas, y empieza a emplearse en el campo autoral para hacer referencia a la afectación directa de la obra, en un principio literaria, luego de la aparición de la imprenta, pero entendiendo hoy día que dicha conducta puede recaer sobre cualquier creación que se encuentre protegida.

Resulta habitual encontrar que la legislación autoral no determina ni aclara el concepto de plagio, por lo cual el estudio del mismo se le ha dejado a la doctrina y a la jurisprudencia. Ejemplo de lo anterior se evidencia en la definición presentada por el "Glosario de Derecho de Autor y Derechos Conexos" de la Organización Mundial de la Propiedad Intelectual (ompi), que señala que el plagio "es el acto de presentar como propia, en su totalidad o en parte, la obra de otra persona" 9 .

Asimismo y siguiendo lo expuesto por la doctrina, la jurisprudencia argentina en sentencia de 21 de marzo de 1994 manifiesta que "el plagio es el apoderamiento ideal de todos o de algunos elementos originales contenidos en la obra de otro autor, presentándolos como propios" 10 .

Por otro lado, a nivel comunitario vale la pena indicar que el Tribunal Andino de Justicia ha tomado lo manifestado por la doctrina en las interpretaciones prejudiciales 10-IP-99 y 139-IP-2003 respecto del concepto de plagio, destacándose de la primera que "la materia del plagio son las obras intelectuales, es decir, las obras de ingenio literarias, artísticas o científicas susceptibles de ser reproducidas por cualquier medio. El carácter de obra intelectual estará dado por su originalidado individualidad. Esta nota es la causa de su protección. Su falta obstará a la misma" (resaltado del Tribunal) ${ }^{11}$.

Igualmente, en la interpretación prejudicial 139-IP-2003 del Tribunal Andino de Justicia es importante señalar que este órgano hace referencia a que si bien la norma comunitaria no presenta una definición explícita sobre el plagio,

9. Boyta, Gyorgy. Glosario de derecho de autor y derechos conexos. Ginebra, ompi, 1980, voz 188 .

10. Lipszyc, Delia. Derecho de autor y derechos conexos, Unesco-Cerlalc-Zavalía, 1993, p. 567, citado en Antequera, Parilli, Ricardo. Plagio. Marco Conceptual. Argentina. Cámara Nacional de Apelaciones en lo Civil, Sala G. 21 de marzo de 1994. Jurisdicción Judicial (civil). Texto del fallo en "Jurisprudencia Argentina" (1994-Iv), 410. M. Venancio vs. Julio y otros. En: Centro Regional para el Fomento del Libro en América Latina y El Caribe, Cerlalc, p. 2. Disponible en: www.cerlalc.org/derechoenlinea/dar/index. php? mode=archivo\&id=905 Consultado el 6 de mayo de 2015 .

11. Iribarne, Rodolfo Antonio y Retondo, Hilda. "Plagio de Obras Intelectuales", en "Los ilícitos civiles y penales en Derecho de Autor", en iI Conferencia Continental de Derecho de Autor. Buenos Aires, Instituto Interamericano de Derecho de Autor (IIDA), 1981, p. 110, citado en Tribunal de Justicia de la Comunidad Andina. Proceso 10-IP-99. LeXIs S.A. vs. la empresa Productora e Información Compañía Ilimitada (prodinfo). Quito, Ecuador, 11 de junio de 1999, p. 11. Disponible en: http:// view.officeapps.live.com/op/view.aspx?src $=$ http $\% 3 \mathrm{~A} \% 2 \mathrm{~F} \% 2$ Fintranet.comunidadandina. org\%2FDocumentos\%2FProcesos\%2F10-ip-99.doc Consultado el 6 de mayo de 2015. 
dicho cuerpo normativo se encuentra dirigido a proteger la obra respecto de esta conducta, por lo que establece que la misma puede afectar tanto la esfera moral como la patrimonial de los derechos que recaen sobre la obra ${ }^{12}$.

En consecuencia de los conceptos doctrinarios, la jurisprudencia internacional y las interpretaciones prejudiciales anteriormente expuestas, puede observarse que en la actualidad no existe un concepto unívoco sobre el plagio; sin embargo, las fuentes del derecho mencionadas se han encargado de categorizar y delimitar sus elementos constitutivos. De esta manera, resulta importante proceder a mencionarlos.

\section{I.I. Tipos DE Plagio}

Doctrinariamente se ha señalado la existencia de dos tipos de plagio: el plagio burdo, servil o literal, y el plagio elaborado, simulado o inteligente, tal y como se observa a continuación.

\subsubsection{Plagio servil}

Modalidad de plagio conocido como burdo, servil o literal, donde el plagiador realiza una apropiación textual total o parcial de la obra, respecto de partes o fragmentos de la misma, sin introducir modificaciones en relación con la creación original.

En este caso no existe un cambio trascendental respecto de la obra primigenia, por cuanto se trata de una conducta mecánica por parte de aquel que la ejecuta.

Así, en este tipo de plagio la cuasi identidad salta a la vista, por lo que cualquier persona, incluso del común, puede fácilmente identificar los eventos de una copia literal de la creación, configurándose en todo caso una infracción al derecho de autor.

\subsubsection{Plagio inteligente}

También conocido como imitación elaborada, simulada o inteligente, se caracteriza porque el plagiario toma de la obra prístina partes sustanciales o relevantes y las incorpora en la obra carente de originalidad, modificándolas o introduciéndoles variaciones, con el fin de que no se pueda establecer la ilicitud de una manera

12. Tribunal de Justicia de la Comunidad Andina. Proceso 139-IP-2003. Solicitud de interpretación prejudicial de los artículos 1, 4 literal a), 8, 11 literales a), b), c), 52, 54, 55 de la Decisión 351 de la Comisión del Acuerdo de Cartagena. Quito, Ecuador, 7 de marzo de 2004, pp. 10-13. Disponible en: http://view.officeapps.live.com/op/view. aspx?src=http $\% 3 \mathrm{~A} \% 2 \mathrm{~F} \% 2 \mathrm{Fintranet}$. comunidadandina.org $\% 2 \mathrm{FDocumentos} \% 2 \mathrm{FProcesos} \%$ 2F139-ip-2003.doc Consultado el 6 de mayo de 2015. 
fácil o evidente. Es decir, "el infractor le introduce modificaciones a la creación ajena, la mayoría de las veces para tratar de disimular la apropiación que hace de la producción de otro"13.

Asimismo, este tipo de plagio puede configurarse cuando en la obra carente de originalidad se omite el nombre del autor de los pasajes o elementos agregados, "limitándose a colocar el nombre del autor en los 'agradecimientos' o en la 'bibliografía consultada', o a través de otras menciones meramente incidentales, pues no se está vinculado directamente el nombre del autor como las partes o elementos citados, incurriéndose así no solo en una violación al derecho moral de paternidad, sino también en un fraude a la Ley y en un acto de deshonestidad intelectual" 14 .

En todo caso, una vez son descubiertos aquellos elementos que modificaron o alteraron la creación dotada de originalidad, es posible identificar con propiedad la total similitud existente entre las obras.

Es importante señalar que la demostración de la infracción en este tipo de plagio puede ser mucho más dispendiosa y difícil, ya que el proceder del plagiador es más elaborado que en el plagio servil, por cuanto se recurre a reformas trascendentales respecto de los elementos fundamentales, así como de aquellos subyacentes o no literales de una creación, tales como "los personajes ficticios, su nombre y su caracterización; nombre de lugares ficticios; esquema narrativo de la obra, es decir, la forma en que se suceden las escenas o situaciones que se narran en una obra; estructura argumentativa o composición del texto, tratándose de las obras literarias" 15 .

En todo caso, para la identificación del plagio se debe observar el tipo de obra, con el fin de determinar la identidad existente o la total similitud entre las creaciones en conflicto, teniendo en cuenta para ello más las semejanzas encontradas que las diferencias alegadas.

\section{i.2. Elementos del plagio}

Una vez expuesto el concepto de plagio y las categorías o tipos del mismo, es importante señalar que para que pueda configurarse esta conducta en cualquiera de sus modalidades deben presentarse dos elementos. Veamos.

13. Antequera Parilli, Ricardo. Plagio. Piratería. Diferencias. Perú. Oficina de Derecho de Autor del indecopi. 13 de marzo de 2007. Jurisdicción Administrativa. Cita de la Resolución 1808-2007/TPI-Indecopi. Resolución 86-2007/odA-INdecopi. En: Centro Regional para el Fomento del Libro en América Latina y El Caribe, Cerlalc, p. 1. Disponible en: http://www.cerlalc.org/derechoenlinea/dar/index.php? mode=info\&id=1123 Consultado el 6 de mayo de 2015.

14. Antequera Parilli. Derechos Intelectuales y Derecho a la Imagen en la Jurisprudencia Comparada, cit., p. 100.

15. Monroy Rodríguez, Juan Carlos. Derecho de autor y derechos conexos. Legislación, doctrina y jurisprudencia concordada y comentada. Bogotá, RRA Formación, 2013, p. 311. 


\subsubsection{Utilización no autorizada de la obra ajena}

Este elemento hace referencia a los casos en que el plagiador dispone de la obra de un tercero bajo dos modalidades: la primera, reproduciéndola de manera literal, servil o burda, y la segunda, introduciéndole cambios a la obra prístina con el objeto de hacer pasar desapercibida la copia de la creación, siendo esta última la modalidad de plagio inteligente anteriormente explicada.

En todo caso, en cualquiera de los dos supuestos el individuo que realiza dicha acción hace uso de una creación sin haber sido facultado por el autor o titular para ello.

Es importante destacar que dentro de la órbita de los derechos que ostenta el autor se encuentra la facultad de otorgar autorización para que su creación sea usada por terceros, configurándose de lo contrario una infracción a sus derechos, y pudiendo en tal caso ejercer las acciones legales a que haya lugar dentro del marco legal correspondiente. Así, solo el autor o titular de la obra goza de la facultad de usarla, explotarla o, en ciertos casos, permitir a terceros el uso de su creación.

\subsubsection{Falsa atribución de la autoría}

Respecto de este elemento vale la pena indicar previamente que el derecho moral de paternidad es aquel que tiene el autor a "exigir el reconocimiento de la autoría de la obra en cualquier utilización que de ella se haga [...]. Este surge sin necesidad de ninguna formalidad, por el sólo acto de la creación, se haya o no publicado la obra" ${ }^{16}$.

En este caso, la falsa atribución de la autoría como elemento configurativo del plagio hace referencia al evento en que el individuo "se atribuye sobre la obra una paternidad que no le corresponde y que le pertenece exclusivamente al autor de la obra copiada" ${ }^{17}$. De esta manera, se presenta una violación al derecho moral de paternidad, por cuanto el autor es eliminado de la obra, existiendo por parte de quien realice dicha conducta la obligación de indemnizar los perjuicios que haya sufrido el autor o titular de la creación.

16. Corte Suprema de Justicia de Colombia, Sala de Casación Penal. Sentencia 31403 de 28 de mayo de 2010, M.P.: Sigifredo Espinosa Pérez, en Jurisprudencia y Doctrina n. ${ }^{\circ} 463$, julio de 2010, p. 5. Disponible en: http://legal.legis.com.co/frmMainContainer. aspx?Path $=$ jurcol_8496cc0dc7938098e0430a0101518098\&obra $=$ jurcol\&contexto=jurcol_8 496cc0dc7938098e0430a0101518098\&proviene=busqg\&q=plagio $\% 20 \&$ fnpipelines=doc_ highlighter Consultado el 6 de mayo de 2015.

17. Tribunal de Justicia de la Comunidad Andina de Naciones. Proceso 139-IP-2003, cit., p. 10. 
Como ejemplo de este elemento configurativo del plagio puede traerse a colación la sentencia proferida por el Tribunal Superior del Distrito Judicial de Cali ${ }^{18}$ referida a un caso en que el demandado se atribuyó falsamente la autoría de unos libros de educación en idioma extranjero (inglés), generando una infracción al derecho de paternidad del demandado, ya que suprimió de manera intencional el nombre verdadero del autor, haciendo pasar por suyas dichas obras plagiadas; por esa "sola circunstancia, debió indemnizar el perjuicio causado al demandante teniendo en cuenta la afección que a ese producto del intelecto experimenta necesariamente quien lo gestó y el impacto emocional que debió soportar al ver cómo se hacía circular por persona diferente" 19 .

Asimismo, se puede mencionar sobre este tema la sentencia proferida por la Cámara Nacional de Apelaciones en lo Civil, Sala F, de Argentina, respecto de un caso donde el autor de unas obras fotográficas demandó a una editorial y a tres personas naturales, por haber empleado sin su autorización ese material y haber atribuido la autoría a personas diferentes a él, publicándolas posteriormente en la revista Gente, situación que llevó a la Cámara a establecer que la falsa atribución de autoría en cabeza de personas diferentes al autor original de dichas creaciones genera un agravio moral, por cuanto se "desgarró al autor una porción de su personalidad" 20 .

\section{i.3. El plagio en la jurisprudencia colombiana}

En contraste con la conceptualización y desarrollo del plagio previamente expuesta se observa que la jurisprudencia en Colombia no ha tratado con rigor y profundidad el tema del plagio; sin embargo y pese ello, es importante mencionar que la jurisdicción penal ha sido la única que se ha pronunciado de fondo sobre esta conducta, esto en la sentencia de la Sala de Casación Penal 31403 de 28 de mayo de 2010, referida al plagio cometido por la docente Luz Mery Giraldo DE JARAMILlo respecto de la tesis de la estudiante Rosa María Londoño Escobar.

18. Antequera Parilli, Ricardo. Daño moral. Apreciación. Paternidad. Plagio. Colombia. Tribunal Superior del Distrito Judicial de Cali. 12 de marzo de 1993. Jurisdicción Judicial (civil). Texto del fallo en copia original. Recurso de apelación contra decisión del Juzgado 8. ${ }^{\circ}$ Civil de Cali. En: Centro Regional para el Fomento del Libro en América Latina y El Caribe, Cerlalc. Disponible en: http://www.cerlalc.org/derechoenlinea/dar/ index.php? mode=info\&id=880 Consultado el 6 de mayo de 2015.

19. Ibíd.

20. Antequera Parilli. Daño moral. Apreciación. Paternidad. Plagio. Argentina. Cámara Nacional de Apelaciones en lo civil, Sala F. 14 de octubre de 1991. Jurisdicción Judicial (civil). Texto del fallo en "La Ley" (1992-B), 475-479, Daniel H. vs. Editorial A., S.A. En: Centro Regional para el Fomento del Libro en América Latina y El Caribe, Cerlalc, p. 6. Disponible en: http://www.cerlalc.org/derechoenlinea/dar/index.php? $\operatorname{mode}=\mathrm{info} \& \mathrm{xid}=878$ Consultado el 6 de mayo de 2015. 
En este caso, la Corte indicó respecto del plagio que es "la apropiación indebida de la creación de otro" 21 , así como aquel "asociado a esa grosera vulneración del principio de paternidad que consiste en tomar lo de otro y hacerlo parecer propio" ${ }^{22}$. Pero también precisó que no solamente se vulnera este derecho, sino también el derecho de integridad, cuando la conducta va dirigida a disfrazar el contenido de la obra original en la plagiada, pero manteniendo en esencia su expresión formal, "así se trate de ocultar el hecho con simples cambios insustanciales de palabras, pues, en ese caso no existe creación libre del individuo, fruto de su propia individualidad, sino evidente apropiación de lo ajeno"23.

Igualmente y siendo concordante con la doctrina y jurisprudencia nacional e internacional, manifestó la Corte que el plagio puede desarrollarse bajo dos modalidades: bien sea la del plagio burdo o servil, situación que se presentó en este caso, puesto que la señora Luz Mery Giraldo de Jaramillo incorporó en su artículo párrafos completos sin citar la fuente original, o bien la del plagio inteligente o simulado, entendido como aquel en que "no se reproduce la obra de una manera idéntica sino que [se] la imita en sus extremos esenciales" ${ }^{24}$.

Es conveniente indicar que con esta sentencia se abrió la puerta a que en Colombia el plagio sea efectivamente reconocido como un ilícito penal, por cuanto al haber realizado una interpretación extensiva de la norma mediante la aplicación del principio pro homine, y teniendo en cuenta que el derecho moral es un derecho humano fundamental, es procedente sancionar dicho proceder en aquellos casos en que se publique total o parcialmente, sin autorización previa y expresa del titular del derecho, una obra, ya sea inédita o divulgada.

De esta manera, hoy día es válido afirmar que de acuerdo a la interpretación realizada por la Sala a través del criterio de interpretación de derechos humanos reseñado en el párrafo anterior, se buscó armonizar la norma interna (Código Penal) con las normas internacionales (tratados internacionales pertenecientes al bloque de constitucionalidad), con el fin de precisar que la conducta de plagio puede predicarse tanto respecto de obras que tienen el carácter de inéditas como de aquellas que ya han sido divulgadas, permitiéndole a los jueces de esta jurisdicción aplicar el artículo en mención en ambos eventos, a fin de proteger los derechos morales del autor o creador de una obra.

Sin embargo es importante mencionar que esta decisión ha sido ampliamente criticada, por cuanto, tal y como lo menciona el jurista ERnesto Rengifo García,

21. González Gómez, Alejandro. El tipo básico de los delitos contra la propiedad intelectual. Madrid, Tecnos, p. 192, citado en Gaviria Londoño, ob. cit., p. 554. En: Corte Suprema de Justicia de Colombia, Sala de Casación Penal. Sentencia 31403 de 28 de mayo de 2010, cit., p. 30.

22. Ibíd., p. 31.

23. Ibíd., p. 39.

24. Ibíd., p. 33. 
con ella se evidencia la constitucionalización del derecho penal, al haber entrado la Sala a hacer una interpretación de la norma en mención ${ }^{25}$. Finalmente y para concluir, si bien no se han producido más pronunciamientos hasta la fecha en materia penal, es factible que en los casos venideros esta sentencia sea tomada como fundadora de una línea jurisprudencial, con el fin de que se dé una ratificación sobre la misma subregla de derecho, al ser pionera respecto del estudio del plagio en Colombia.

\section{i.4. El plagio en la doctrina colombiana}

Por lo general, al hacer referencia al plagio este es asociado a la conducta que "consiste en copiar los escritos de un tercero y presentarlos como propios" 26 . Sin embargo, es conveniente mencionar que hoy día, como se sabe, el plagio no solo se predica de las obras literarias sino respecto de obras de cualquier género, aunque sea más común y fácil detectar esta conducta en relación con creaciones de tipo escrito.

La doctrina colombiana presenta y expone diferentes acepciones del plagio, teniendo en cuenta que dicha conducta es dinámica y se encuentra en constante evolución. A modo ejemplificativo, puede mencionarse lo expuesto por el jurista Juan Carlos Monroy, quien retoma lo manifestado por la Dirección Nacional de Derecho de Autor al indicar que el plagio es "la apropiación ilegítima de la paternidad de la obra de otro, es decir, el apoderamiento literal o simulado de todos o de algunos elementos originales contenidos en la obra de otro autor, presentándolos como propios, siendo condición necesaria el conocimiento del plagiario de la obra plagiada" 27 .

En similar sentido, Alejandro González Gómez señala que el plagio es "la apropiación indebida de la creación de otro" 28 .

De esta manera, puede mencionarse como elemento fundamental de estas definiciones la apropiación ilegítima que realiza un tercero respecto de los elementos dotados de originalidad de una obra que existía previamente, apropiación que se puede efectuar mediante dos modalidades principales: burda o servil, o con modificaciones maquilladas a fin de que su proceder no sea descubierto.

25. Rengifo García, Ernesto. "¿Es el plagio una conducta reprimida por el derecho penal?”, en Revista La Propiedad Inmaterial (2010), n. ${ }^{\circ}$ 14, p. 304.

26. Organización de las Naciones Unidas para la Educación,la Ciencia y la Cultura, unEsco. El ABC del derecho de autor. Mayenne, Imprimerie de la Manutention, 1981, p. 64.

27. Monroy Rodríguez. Derecho de autor y derechos conexos. Legislación, doctrina y jurisprudencia concordada y comentada, cit., Concepto dado por la Dirección Nacional de Derecho de Autor, pp. 307-308.

28. González Gómez, ob. cit., p. 192. 
Por otro lado, la Dirección Nacional de Derecho de Autor, como máxima autoridad en la materia, señala en concepto jurídico que el plagio "básicamente consiste en hacer que aparezca como propio lo que pertenece a otros (apoderamiento legal de todos o algunos elementos originales), habiendo dolo o mala fe en el acto que produjo el daño al arrebatar a otro el mérito de la creación, es decir, al usurpar la condición de autor"29.

Es fundamental recalcar que en esta definición se presenta el dolo o la mala fe de la persona que realiza el comportamiento infractor, por cuanto esta conoce la acción, tiene la intención y realiza la conducta. Es relevante resaltar que dicho concepto se dirige más hacia el plagio en materia penal, puesto que en lo civil el dolo es irrelevante, por cuanto la responsabilidad que se genera en su "mayoría es de naturaleza extracontractual"30.

Habida cuenta de lo anterior, puede mencionarse nuevamente que no se presenta una definición única y unánime de la figura jurídica del plagio, al incluirse en ella elementos dispares, aunque, como se desprende de lo anteriormente expuesto, los elementos constitutivos de dicha conducta se conservan incólumes.

Asimismo, es importante destacar que no existe a nivel normativo una definición de esta conducta, que permita unificar y zanjar las diferencias entre los conceptos presentados, siendo labor netamente de la doctrina y la jurisprudencia, como se puso de presente con anterioridad, la definición, desarrollo y exposición del plagio en sus diversas modalidades.

Finalmente y con independencia de la falta de unicidad en cuanto a una definición del concepto en nuestro país, la realización de esta conducta deviene en una responsabilidad de tipo penal, aunque también puede ser objeto de responsabilidad civil ante esta jurisdicción, pese a que hoy en día no existen mayores pronunciamientos sobre la materia.

En todo caso, es trascendental, en función de la modalidad de plagio que se llegue a desarrollar, observar que este puede afectar tanto los derechos morales como patrimoniales con que cuenta el autor o titular de una obra, cualquiera que ésta sea, debiéndose hacerse un examen riguroso de cuáles son los elementos dotados de originalidad y que componen la obra, para así determinar la existencia o inexistencia de una vulneración.

La realización de ese examen es factible a partir de la aplicación de un método sistemático que permita, en el curso de un proceso, comparar y contrastar diferentes tipos de obras, para así evaluar la calidad de las semejanzas sustanciales

29. Convenio Antipiratería para Colombia. Derecho de autor y derechos conexos en Colombia. Aspectos juridicos. Herrera Osorio, Fredy Andrei (comp.). 2. a ed., Bogotá, Panamericana formas e impresos, 2008, p. 433.

30. Antequera Parilli, Ricardo. Derechos Intelectuales y Derecho a la Imagen en la Jurisprudencia Comparada, cit., p. 190. 
existentes. De ahí que sea imperioso acudir al estudio de casos que ofrece el derecho comparado y que permiten definir y proponer un procedimiento estructurado en una serie de pasos para ser implementado y aplicado en Colombia, en nuestro caso respecto del análisis en lo que atañe al plagio en la obra cinematográfica.

Para ello y tal como se verá más adelante, se traen a colación tres casos importantes de la jurisprudencia de Estados de Unidos y que sentaron las bases para la detección del plagio en relación con diferentes tipos de obras.

\section{El CONCEPTO de Similitud SUSTANCiAl COMO ESTÁNDAR APLICABLE EN LOS EVENTOS DE PLAGIO INTELIGENTE}

Este criterio o estándar es empleado para hacer referencia a los eventos en los que se detecta la existencia de una copia respecto de las "coincidencias estructurales, básicas y fundamentales de una obra ajena" ${ }^{31}$. La similitud sustancial es de primordial aplicación por los jueces para establecer la existencia del plagio de tipo simulado o inteligente, ya sea total o parcial, teniendo en cuenta que el plagiador realiza toda clase de deformaciones en pro de ocultar aquellos elementos originales de la creación que son apropiados e incorporados en la obra plagiaria.

Es pertinente mencionar que este criterio está dirigido entonces a detectar las semejanzas esenciales entre las obras, y no la identidad o coincidencia de las mismas, ya que esta última correspondería a la modalidad burda de plagio, donde es innecesaria la aplicación de la similitud sustancial, por cuanto dicha conducta salta a la vista incluso para un observador promedio.

Por consiguiente, el análisis de semejanzas relevantes se referirá a la expresión de las formas y no a las ideas, ya que de no hacerse así, la valoración sería incorrecta, por cuanto el análisis no puede versar sobre los meros conceptos ni sobre aquellos contenidos pertenecientes al dominio público.

Igualmente, la comparación no puede depender de los elementos disímiles que aparezcan entre las obras, por cuanto en este último escenario el análisis estaría mal enfocado, pudiendo dar cabida al estudio de elementos no susceptibles de protección, como ya se mencionó, así como también se generaría un escenario propicio para dejar impune el actuar del plagiador, quien se valdría de la existencia de diferencias notables entre las creaciones con el fin que no se sancione su proceder.

31. Antequera Parilli, Ricardo. Plagio. Apreciación de las semejanzas. Obra Didáctica. España. Audiencia Provincial de Almería, Sección 3. a 10 de junio de 2004. Jurisdicción Judicial (civil). Texto del fallo disponible en el Portal del Consejo General del Poder Judicial de España: http://www.poderjudicial.es/jurisprudencia, Sentencia 141/04. En: Centro Regional para el Fomento del Libro en América Latina y El Caribe, Cerlalc, p. 3. Disponible en: http://www.cerlalc.org/derechoenlinea/dar/index.php? mode=info\&id=1625 Consultado el 6 de mayo de 2015. 
En todo caso, este criterio busca resolver el interrogante de si es posible que entre obras del mismo o diferente género pueda presentarse una similitud respecto de sus estructuras básicas y fundamentales que van más allá de los meros conceptos o contenidos de dominio público. En caso de ser afirmativa la respuesta, indudablemente el juez se encontrará en presencia del plagio como violación directa de los derechos de autor; en caso contrario, si las coincidencias son respecto de aspectos banales, no será posible hablar de la existencia per se de una vulneración, ya que estos no son protegibles.

Sobre este punto es importante hacer hincapié en que tanto en Colombia como en otros países este criterio es de aplicación predominante en los eventos de plagio de creación del intelecto. Puede indicarse, por ejemplo, que en España, en las sentencias sTs de 28 de enero de 1995 (conflicto entre obras arquitectónicas, planos o diseños científicos para viviendas) ${ }^{32}$, sTs de 17 de octubre de 1997 (conflicto entre bases de datos: listados informativos sobre las industrias y empresas de las provincias de Álava, Bilbao y Guipúzcoa) ${ }^{33}$ y sTs de 23 de marzo de 1999 (conflicto entre obras literarias (reportajes) que incluyen material gráfico (fotografías) ${ }^{34}$, se hace mención al plagio inteligente cuando "no existe propiamente una absoluta identidad sino una 'total similitud', encubierta con 'ardides y ropajes que las disfrazan'". Y esta "ha de referirse a las coincidencias estructurales básicas y fundamentales y no a las accesorias, añadidas, superpuestas o modificaciones no trascendentales" ${ }^{35}$. En este caso, la similitud sustancial es tenida en cuenta como criterio para la determinación del plagio $^{36}$, partiendo del análisis de

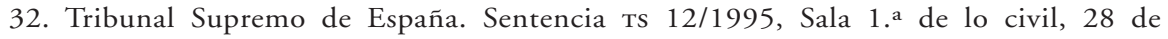
enero de 1995. Recurso de Casación. Ponente: Villagómez Rodil, Alfonso. Disponible en: http://supremo.vlex.es/vid/honorarios-intelectual-plagio-proyecto-ba-ma-17741522 Consultado el 6 de mayo de 2015.

33. Tribunal Supremo de España. Sentencia ts 886/1997, Sala 1.a de lo civil, 17 de octubre de 1997. Recurso de Casación n. ${ }^{\circ}$ 2654/1993. Ponente: Fernández-cid de Temes, Eduardo. Disponible en: http://www.uclm.es/profesorado/jjmarin/tema_2.doc Consultado el 6 de mayo de 2015 .

34. Tribunal Supremo de España. Sentencia ts 237/1999, Sala 1. a de lo civil, 23 de marzo de 1999. Recurso de Casación n.o 2935/1994. Ponente: García Varela, Román. Disponible en: http://www.poderjudicial.es/search/doAction?action=contentpdf\&database match $=$ TS\&reference $=2943750$ \&links $=$ \&optimize $=20031203 \&$ publicinterface $=$ true Consultado el 6 de mayo de 2015.

35. Antequera Parilli, Ricardo. Plagio. Marco Conceptual. Plagio simulado. España. Audiencia Provincial de Madrid, Sección 11. a 6 de junio de 2007. Jurisdicción Judicial (civil). Texto del fallo disponible en el portal del Consejo General del Poder Judicial de España: http://www.poderjudicial.es/jurisprudencia, Sentencia 455/2007. En: Centro Regional para el Fomento del Libro en América Latina y El Caribe, Cerlalc, p. 5. Disponible en: (http://www.cerlalc.org/derechoenlinea/dar/index.php? mode=info\&id=1621 Consultado el 6 de mayo de 2015.

36. Tribunal Supremo de España. Sentencias ssts 28 de enero de 1995, 17 de octubre de 1997, 23 de marzo de 1999, 27 de enero de 2001, 23 de octubre de 2001, 26 de noviembre de 2003. 
las semejanzas existentes entre las creaciones en conflicto que permitan establecer que el producto plagiario es una copia de la obra prístina que ha sido deformada.

En el mismo sentido, en Perú, retomando lo señalado por la doctrina española al aplicar a la comparación de las obras el criterio de la similitud sustancial, ha indicado la Sala de Propiedad Intelectual del Tribunal de INDECOpI que el plagiario “a través de esta conducta se aprovecha de la labor creadora de otro, para lo cual copia sustancialmente la obra y aparenta ser su auténtico creador" ${ }^{37}$; por lo que el evento de plagio inteligente "debe apreciarse por las semejanzas y no por las diferencias que presentan las obras implicadas" 38 . Como ejemplo de los postulados anteriores se puede mencionar la Resolución 1266-2008/TPI-INDECOPI ${ }^{39}$, respecto de un conflicto por la reproducción de dos personajes de una obra literaria en otra haciendo pasar por propio lo que en realidad pertenecía a terceros al momento de presentar la solicitud de registro de la obra ante la Oficina Nacional; se afectó así el derecho moral de paternidad al atribuirse el demandado falsamente la autoría de los personajes y el derecho de reproducción sin tener autorización para incluirlos en la obra infractora.

En la misma línea argumentativa se puede hacer referencia a Chile, donde la Corte Suprema de Justicia, al estudiar la demanda interpuesta por Racimec Chile S.A., sociedad encargada de explotar y prestar servicios de software y procesamiento de datos, contra la Universidad de Concepción, advirtió la importancia de la similitud sustancial en el análisis de dos soportes lógicos empleados para la realización de juegos y sorteos de azar (lotería KINO), indicando que "para determinar una eventual copia esta debe medirse por las semejanzas y no por las diferencias" ${ }^{\text {}}{ }^{0}$.

37. Delgado Porras, Quintano Ripollés y García Rivas, citados en Valbuena Gutiérrez, José. Las obras o creaciones intelectuales como objeto del Derecho de Autor. Granada, Comares, 2000, p. 141. En: Antequera Parilli, Ricardo. Plagio. Marco conceptual. Plagio de coautor. Obra en colaboración. Perú. Tribunal de Defensa de la Competencia y de la Propiedad Intelectual de indecopi. Sala de Propiedad Intelectual. 1 de junio de 2009. Jurisdicción Administrativa. Texto digitalizado de la Resolución, cortesía INDECOPI. Resolución 1382-2009/TPi-Indecopi. En: Centro Regional para el Fomento del Libro en América Latina y El Caribe, Cerlalc, p. 22. Disponible en: http://www.cerlalc.org/ derechoenlinea/dar/index.php?mode=info\&id=2021 Consultado el 6 de mayo de 2015; Antequera Parilli, Ricardo. Plagio. Marco Conceptual, Apreciación en concreto. Derechos Infringidos. Perú. Sala de Propiedad Intelectual del Tribunal de indecopi. 29 de mayo de 2008. Jurisdicción Administrativa. Texto digitalizado de la Resolución, cortesía del indecopi. Resolución 1266-2008/Tpi-indecopi. En: Centro Regional para el Fomento del Libro en América Latina y El Caribe, Cerlalc. Disponible en: http://www.cerlalc.org/ derechoenlinea/dar/index.php?mode=info\&id=1501 Consultado el 6 de mayo de 2015.

38. Delia Lipszyc, ob. cit., p. 567, citado en Antequera Parilli, Ricardo. Plagio. Marco Conceptual, Apreciación en concreto. Derechos infringidos, cit., p. 2.

39. Ibíd.

40. Antequera Parilli, Ricardo. Plagio. Apreciación de las semejanzas. "Software”. Chile. Corte Suprema de Justicia. 15 de septiembre de 1999. Jurisdicción Judicial. Texto del fallo en copia del original. Sfeir y otros vs. Universidad de Concepción. En: Centro Regional 
De lo anterior se evidencia que en la aplicación de la similitud sustancial prevalecen las semejanzas por encima de las disparidades, para fines de evidenciar el plagio. Adicionalmente, ese parecido debe predicarse de aquellos elementos que revisten a la obra de una originalidad y creatividad singular, como se ha hecho mención.

Por otra parte, los circuitos federales de Estados Unidos, de manera general, hacen referencia principalmente a dos escenarios donde puede configurarse la infracción, dependiendo de si hay o no múltiples formas de expresar la creación y darle desarrollo a una idea. El primer evento hace alusión a cuando "existe una limitada gama de expresión (por ejemplo, hay solo determinadas formas de pintar una pelota saltarina roja en un lienzo blanco), entonces la protección de derecho de autor es 'limitada' y una obra debe ser 'virtualmente idéntica' para ser infractora" ${ }^{\prime 1}$. En este caso, la creación plagiaria habrá de ser equivalente al trabajo prístino que ha sido deformado a causa de este para aplicar este criterio.

El segundo escenario corresponde al criterio de la similitud sustancial, que es empleado en los eventos en que hay "una amplia gama de expresión (por ejemplo, hay millones de formas de hacer una película sobre ataques alienígenas), entonces la protección del derecho de autor es 'amplia' y una obra será infractora si es 'sustancialmente similar' a la obra protegida por derecho de autor" ${ }^{\prime 2}$.

Sobre el particular puede manifestarse que si bien el estándar de la similitud sustancial en el caso norteamericano tiene un enfoque de corte utilitario, este permite establecer, mediante su aplicación, al igual que en los otros países anteriormente mencionados, la existencia de semejanzas esenciales que llevan a declarar y sancionar la configuración de la mencionada conducta.

Como consecuencia, la jurisprudencia norteamericana ${ }^{43}$, y en especial el "Noveno Circuito de Apelaciones especializado en infracciones referentes a la

para el Fomento del Libro en América Latina y El Caribe, Cerlalc, p. 17. Disponible en: http://www.cerlalc.org/derechoenlinea/dar-TELmex/index.php? $\operatorname{mode}=\operatorname{archivo} \& \mathrm{id}=910$ Consultado el 6 de mayo de 2015.

41. Antequera Parillit, Ricardo. Plagio. Apreciación en concreto. Idea y forma de expresión. Elementos intrínsecos y extrínsecos. Muñecas. Estados Unidos de América. Corte de Apelaciones para el 9. ${ }^{\circ}$ Circuito. 22 de julio de 2010. Jurisdicción Judicial (Civil). Texto del fallo en: http://www.ca9.uscourts.gov/. Traducción Espinal, Melisa. RNB. Mattel, Inc., y otros vs. MGA Entertainment, Inc. y otros. n. ${ }^{\circ}$ 09-55812. D.C. n. ${ }^{\circ}$ 2:04-cv-09049-sgl. En: Centro Regional para el Fomento del Libro en América Latina y El Caribe, Cerlalc, p. 13. Disponible en: http://www.cerlalc.org/derechoenlinea/dar/ index.php? mode=info\&id=2130 Consultado el 6 de mayo de 2015 .

42. Ibíd.

43. Los Circuitos "Segundo, Sexto y Noveno de apelaciones de los Estados Unidos de América, han creado sus propios test y/o modelos analíticos de abstracción, reduccionistas o de disección para efectos de distinguir entre los dos elementos esenciales involucrados dentro del concepto de similitud sustancial": Castellanos, Carlos. "Ajustes iusteóricos y metodológicos acerca de la dicotomía idea/expresión: las aproximaciones y desarrollos 
industria cinematográfica" ${ }^{44}$, aplica el criterio de la similitud sustancial a través de un test de varios pasos (prueba dual o "substantial similarity test" ${ }^{45}$ ), que le permite diferenciar los elementos susceptibles de protección respecto de aquellos banales, para así decidir si se presenta un parecido significativo entre las producciones intelectuales en conflicto.

En igual sentido, los demás circuitos aplican diferentes pruebas o exámenes con miras a hallar las similitudes fundamentales entre las creaciones; así por ejemplo, el Décimo Circuito emplea el "Abstraction Test" o "Test de Abstracción"46, que es comúnmente usado en los casos en que se debe determinar una infracción a los derechos de autor cuando la obra corresponde a un programa de ordenador. Asimismo, se encuentran: "The Copying and Improper-Appropriation Test" o "Test de copia y apropiación indebida", y "The Total Concept and Feel Test" o "Test del concepto total y el sentir de la prueba", entre otros, todos ellos dirigidos a poner en evidencia la presunta infracción.

En este entendido, si bien es cierto que se presentan diferencias respecto del enfoque de la similitud sustancial entre los dos sistemas jurídicos (en los países que aplican el régimen jurídico de corte europeo este criterio no atiende de manera primordial a un fin económico, ya que se tiene en cuenta al autor y los derechos morales que este detenta), es válido tener presente para la determinación del plagio, en los países pertenecientes tanto a uno como a otro régimen, este criterio, por cuanto su empleo permite establecer si se ha dado la efectiva apropiación de aquellos elementos revestidos de originalidad y que son incorporados en otra obra, y en todo caso, a través del análisis de las semejanzas existentes, permite revelar y sacar a la luz igualmente todos aquellos elementos que no son literales, pero que han sido disfrazados y apropiados indebidamente por el plagiador, aunque siguen manteniendo en esencia la impronta del autor.

Asimismo, este criterio en Estados Unidos se aplica en aquellos casos donde el afectado no ha podido demostrar que el infractor tuvo un conocimiento

jurisprudenciales que las Cortes norteamericanas han experimentado en el entendimiento y análisis de la dicotomía idea/expresión", en Revista Iberoamericana de Derecho de Autor: Estudios, Jurisprudencia, Centro Regional para el Fomento del Libro en América Latina y El Caribe, cerlalc, año V, n. ${ }^{\circ}$ 10, julio-diciembre de 2011, p. 47.

44. Es importante resaltar que los diversos circuitos norteamericanos, tal y como ya se mencionó, aplican sus propios test sin ser exclusivos o excluyentes unos con otros; sin embargo, en el presente se considera importante tener en cuenta y hacer alusión, en lo que corresponda, a los casos resueltos por este circuito, dada la experticia del mismo en materia de industria cinematográfica.

45. Osterberg, Robert C. y Osterberg, Eric C. "Chapter 3: Tests for Substantial Similarity", en Substantial Similarity in Copyright Law. New York, United States of America: PLI-Practising Law Institute. 2014, 3-2. Disponible en: http://www.pli.edu/public/ booksamples/631_sample3.pdf Consultado el 6 de mayo de 2015.

46. Ibíd., 3-3. 
previo o acceso a la creación, pero busca probar que entre ambas obras existen estrechas semejanzas que ocasionan que el plagio deba ser sancionado. Si bien la evidencia del acceso y la similitud sustancial entre las obras en ciertos casos de la jurisprudencia norteamericana se han establecido como requisitos concurrentes ${ }^{47}$, en otros se permite que pese a no poderse demostrar el acceso, pueda acudirse a señalar tales similaridades mediante la aplicación de este criterio ${ }^{48}$.

Por otro lado, vale la pena destacar que algunos tribunales, como el de Apelaciones del Onceavo Circuito, aluden es al concepto de "similitud notable o sorprendente", y no a la "similitud sustancial", entendido el primero como aquel estándar superior donde la "similitud en apariencia es tan notable, que como cuestión práctica, se excluye la posibilidad de una creación independiente, coincidencia o fuente común previa" ${ }^{49}$.

Finalmente y teniendo en cuenta lo mencionado en párrafos anteriores, las Cortes de los doce circuitos federales de Estados Unidos aplican diferentes exámenes, pruebas o test para determinar la infracción respecto de la obra, por lo cual el análisis de la similitud sustancial tiende a variar dependiendo del circuito y del test que se realice.

\section{LA DisCUSión EN TORNO A LA EXTENSIÓN DEL PLAGIO}

Como se ha hecho mención, la originalidad de la obra puede predicarse respecto de toda o parte de ella.

En este mismo sentido, el plagio puede configurarse en relación con toda la creación o con una parte fundamental de la misma, teniendo en cuenta que esta conducta busca "dar por propio el trabajo ajeno desfigurado, utilizar en lo sustancial obras ajenas dándolas como propias, cualquiera sea su extensión. Pero también es necesario que sea más que una ‘inspiración’ y que la parte imitada de la obra plagiada hubiera constituido fundamento original y novedoso de la obra anterior" ${ }^{50}$. De esta manera, el plagio se predica en relación con aquellos elemen-

47. Corte de Apelaciones del Séptimo Circuito de Estados Unidos. Selle v. Gibb $741 \mathrm{f}$. 2d 896 (7th Cir. 1984) Judge Cudahy. Disponible en: http://mcir.usc.edu/cases/1980-1989/ Pages/sellegibb.html Consultado el 6 de mayo de 2015.

48. Antequera Parilli, Ricardo. Plagio. Apreciación en concreto. Rechazo. Creación independiente. Idea y forma de expresión. Pintura. Parque temático. Estados Unidos de América. Tribunal de Apelaciones para el 11. ${ }^{\circ}$ circuito. 2 de noviembre de 2006. Jurisdicción Judicial Civil. Texto del fallo disponible en: http://www.ca11.uscourts.gov. Traducción Melisa Espinal. 02-01377-Cv-ORL-19Krs. Orrin Monroe Corwin vs. Walt Disney Company. En: Centro Regional para el Fomento del Libro en América Latina y El Caribe, Cerlalc, p. 14. Disponible en: http://www.cerlalc.org/derechoenlinea/dar/index. php? mode=info\&id=2131 Consultado el 6 de mayo de 2015.

49. Ibíd., p. 14.

50. Isidro Satanowsky, citado por Antequera Parilli, Ricardo. Objeto del derecho. 
tos esenciales y que son objeto de protección por el derecho de autor, no con las meras ideas o temáticas, ya que estas, como se ha estudiado, no son susceptibles de ser apropiadas.

En todo caso e independientemente de si el plagio es total o parcial respecto de alguno de estos elementos, para que se entienda configurada la conducta basta con que se dé la apropiación ajena de alguno de ellos. Por lo tanto, es importante destacar que dicha conducta se predica en relación con la calidad de las coincidencias existentes y no con un número determinado de ellas ${ }^{51}$.

Por consiguiente, la extensión no debe ser analizada en un sentido estrictamente cuantitativo, sino atendiendo igualmente a lo cualitativo en referencia al apoderamiento de los elementos dotados de originalidad y que representan la impronta del creador, para así justificar la existencia de un atentado a la normal explotación de la obra, al igual que un perjuicio injustificado a los intereses del autor o creador; no pudiendo en este caso el plagiador ampararse en las limitaciones y excepciones que brinda la ley, como por ejemplo, el derecho de cita.

Por lo tanto, la extensión en sí misma considerada no se predica de un número concreto de elementos copiados, sino de aquellos que han sido incorporados a la obra plagiaria y que ostentan características que permiten que la creación sea protegida por el derecho de autor. Situación que pone de presente que la valoración de la extensión, como ya se mencionó, no se rige por un aspecto rigurosamente cuantitativo sino también por uno cualitativo, por lo que basta que haya apropiación de un solo elemento para que se entienda configurado el plagio y, en esa medida, este deba ser sancionado.

Como consecuencia de lo expuesto, la extensión debe ser analizada por el operador judicial en función del caso en concreto, por cuanto puede suceder que dicha conducta se configure tan solo sobre una parte mínima, pero si esta es trascendental en la obra preexistente ${ }^{52}$, dicho proceder debe ser castigado.

Forma de expresión. Uso de las ideas. Obra científica. Argentina. Cámara Nacional de Apelaciones en lo Civil, Sala A. Octubre de 2006. Jurisdicción Judicial (Civil). Biblioteca Jurídica Online, disponible en: http://www.eldial.com/ Referencia AA39B. Giangreco, Luis vs. Editorial Errepar S.A. En: Centro Regional para el Fomento del Libro en América Latina y El Caribe, Cerlalc, p. 7. Disponible en: http://www.cerlalc.org/derechoenlinea/ dar/index.php? mode=info\&id=1560 Consultado el 6 de mayo de 2015.

51. Antequera Parilli, Ricardo. El registro. Efectos. Omisión. Irrelevancia en caso de plagio. Argentina. Cámara Nacional de Apelaciones en lo Civil, Sala E. 20 de octubre de 2005. Jurisdicción Judicial Civil. Biblioteca Jurídica Online, disponible en: http://www. eldial.com.ar/ Referencia AA303C. Causa 430819. Arce, Rodolfo Adrían vs. Suar, Adrián y otros. En: Centro Regional para el Fomento del Libro en América Latina y El Caribe, Cerlalc, p. 4. Disponible en: http://www.cerlalc.org/derechoenlinea/dar/index. php? mode=info\&id=1593 Consultado el 6 de mayo de 2015.

52. Antequera Parilli, Ricardo. Daño moral. Elementos para su apreciación. Plagio. Extensión del plagio. Brasil. Novena Cámara Civil del Tribunal de Justicia del Estado de Rio Grande Do Sul. 10 de agosto de 2011. Jurisdicción Judicial Civil. Texto del fallo 
En conclusión sobre este punto y teniendo en cuenta lo expuesto, el juez para identificar la existencia de la vulneración debe aplicar las reglas de la sana crítica, valorar en conjunto los hechos fácticos y legales, con apoyo en diversos medios de prueba, entre ellos el dictamen pericial, siendo esta la prueba relevante en este tipo de infracciones, tal y como se expone a continuación.

\section{Necesidad del juez de estar asistido por un perito para LA VALORACIÓN DEL PLAGIO EN MATERIA AUdiOVISUAL}

El legislador ha permitido que se pueda acudir ante diferentes jurisdicciones, mediante el ejercicio de acciones judiciales ${ }^{53}$, con el fin de tutelar los derechos de autor frente a una posible y eventual vulneración de las prerrogativas morales o patrimoniales que posee el creador o titular de una obra, con independencia del género al que esta pertenezca.

En todo caso, es el juez el encargado de declarar la existencia o no de un plagio respecto de una obra (literaria o artística), teniendo entonces en cuenta cualquier medio probatorio aportado en el curso del proceso y que sea conducente, pertinente, útil y, sobre todo, que lo lleve a un grado de convencimiento tal que le permita decidir sobre la infracción o comisión del delito. Sin embargo, en ciertos casos la complejidad del asunto genera la necesidad de estar asistido en el trámite por un auxiliar especializado en un área determinada, para así esclarecer hechos fundamentales y que son objeto del litigio.

Es por ello que el medio de prueba idóneo dentro de la valoración del plagio en materia audiovisual, y en especial respecto de la obra cinematográfica, es el dictamen pericial, definido como aquel "que consiste en la aportación de ciertos elementos técnicos, científicos o artísticos que la persona versada en la materia de que se trate hace para dilucidar la controversia, aporte que requiere de especiales conocimientos" 54 .

disponible en el portal del Tribunal de Justicia del Estado de Rio Grande Do Sul: http:// www.tjrs.jus.br Traducción Ricardo Antequera Parilli. Apelación civil 7004382717. En: Centro Regional para el Fomento del Libro en América Latina y El Caribe, CerLAlC, p. 1. Disponible en: http://www.cerlalc.org/derechoenlinea/dartelmex/index. php? mode=archivo $\&$ id $=2235$ Consultado el 6 de mayo de 2015.

53. Colombia: jurisdicción penal: acción penal, Ley 599 de 2000, Título viII, Capítulo Único, artículos 270 a 272; jurisdicción civil: medidas civiles, como procedimientos cautelares, procesos ejecutivos o declarativos; jurisdicción contencioso administrativa: cuando una infracción al derecho de autor es imputable a una entidad pública.

54. Parra Quijano, Jairo. Manual de derecho probatorio. La prueba en los procedimientos: civil, penal (ordinario y militar), laboral, canónico, contencioso-administrativo y en el derecho comparado. 16.a ed., Bogotá, Librería Ediciones del Profesional, 2007, p. 633. 
De esta manera, esos conocimientos especiales ${ }^{55}$ dotan al juez de las herramientas necesarias, para valorar mejor la prueba respecto de la existencia o no de un plagio entre una obra originaria y la aparentemente plagiaria, razón por la cual, el dictamen pericial puede llevarse a cabo, aun cuando el juez se encuentre especializado en esta área, ya que si "el funcionario se atuviese a sus propios conocimientos, por profundos que sean, sería tanto como que sin necesidad de testimonios, documentos, etc., tuviera por acreditados determinados hechos" ${ }^{\prime \prime}$.

En consecuencia, en aquellos eventos en que las obras tienen un cierto grado de complejidad por el lenguaje en que se encuentran expresadas, cobran especial relevancia la prueba pericial como medio de prueba y la asistencia de un perito como auxiliar del juez con el fin de verificar los hechos que son el centro de la controversia. En este sentido y a modo de ejemplo, pueden señalarse como obras que requieren de la aplicación de esos conocimientos técnicos, científicos o artísticos:

- Los programas de ordenador o software

- Las bases de datos

- Las partituras musicales

- Las obras arquitectónicas y diseños urbanísticos ${ }^{57}$

- Las obras audiovisuales

En estos casos el dictamen resulta trascendental puesto que orienta al juez acerca de la configuración del plagio respecto de algún elemento original subyacente no literal de la obra, ya sea en todo o en parte de la misma, en los casos de un aparente plagio inteligente. En ese sentido, la prueba pericial debe ser presentada por un perito objetivo e imparcial ${ }^{58}$, apoyado además por todos aquellos documentos que le permitan acreditar su idoneidad y experiencia ${ }^{59}$ en el área de interés y que le sirvan de fundamento para emitir su concepto, ya que de no hacerlo el dictamen "pierde sustento debido a la insuficiencia de sus fundamentos" ${ }^{\circ}$.

Por lo anterior, un dictamen que se presente en el curso de un proceso, ya sea civil o penal, debe señalar y concluir con argumentos y fundamentos sólidos la existencia de un plagio, por ejemplo, en una obra cinematográfica. Adicionalmente, este ha de ser claro, preciso, exhaustivo y detallado, explicando además

55. Art. 226 CGP.

56. Parra Quijano, ob. cit., p. 633.

57. Antequera Parilli, Ricardo. Derechos intelectuales y derecho a la imagen en la jurisprudencia comparada, cit., p. 125.

58. Art. 235 CGP.

59. Art. 226 CGP.

60. Antequera Parilli, Ricardo. Pruebas. Dictamen Pericial. Apreciación. Obra Audiovisual. Guión. Argentina. Cámara Nacional de Apelaciones en lo Civil, Sala I. 05 de agosto de 1999. Jurisdicción Judicial (civil). Texto del fallo en formato papel. Guebel, Norberto vs. Fernández Musiak, Diego. En: Centro Regional para el Fomento del Libro en América Latina y El Caribe, Cerlalc, p. 1. Disponible en: http://www.cerlalc.org/ derechoenlinea/dar/index.php? mode=info\&id=1639 Consultado el 6 de mayo de 2015 . 
cuáles fueron los fundamentos técnicos, científicos o artísticos aplicados al caso, así como los exámenes, métodos, experimentos e investigaciones efectuadas ${ }^{61}$.

Lo anterior le permitirá al juez una comprensión y verificación clara de los hechos aplicando a su vez las reglas de la sana crítica y teniendo en cuenta la solidez, claridad, exhaustividad, precisión y calidad de los fundamentos, la idoneidad del perito y su comportamiento en la audiencia, así como las demás pruebas que obren en el proceso $^{62}$.

Por lo tanto, es imperioso resaltar que si bien el dictamen pericial no es el único medio probatorio válido en materia de plagio, resulta relevante para que el juez lo estime en conjunto con las demás pruebas allegadas en forma regular y oportuna.

Ahora bien, es importante destacar que este medio probatorio puede ser solicitado tanto de manera oficiosa como a petición de parte, teniendo en cuenta exclusivamente las cuestiones objeto de disputa que han de ser verificadas mediante aquellos conocimientos técnicos o científicos de los que pueda carecer el juez.

Así y volviendo al caso que es objeto del presente estudio, el dictamen pericial en materia de derecho de autor resulta realmente pertinente cuando: 1. La obra está expresada en un lenguaje complejo, como en aquellos casos mencionados anteriormente, y 2. Se está en presencia de un posible plagio inteligente o simulado, por cuanto en este evento la detección del mismo requiere de un examen más exhaustivo, ya que el plagiario busca disimular su actuar con cambios que aparentemente dotan a la obra presuntamente vulneradora de una originalidad que en realidad no tiene, o bien se apodera de algunos elementos sustanciales y originales de esa creación trasladándolos a la obra plagiaria, lo que hace que a simple vista no sea posible identificar la infracción.

En este entendido, el auxiliar, mediante la aplicación de sus conocimientos técnicos, científicos o artísticos y de su experticia en el tema, debe examinar todos aquellos elementos estructurales que conforman la obra originaria o inicialmente creada respecto de la presuntamente plagiaria, teniendo en cuenta solamente las partes que revistan un cierto grado de originalidad y reflejen la impronta del autor. Por lo cual cabe analizar las similitudes y no las diferencias entre las creaciones.

No obstante lo mencionado, no se excluye la posibilidad de practicar la prueba pericial también en aquellos casos en que la obra está expresada en un lenguaje de fácil comprensión; por lo tanto, se precisa, lo que ocurre es que el dictamen tiene especial relevancia y resulta de mayor utilidad en el evento mencionado en párrafos anteriores. En todo caso, para su práctica habrán de observarse las reglas del Código General del Proceso y la pertinencia y procedencia del medio 
de prueba con el fin de evitar pruebas superfluas que entorpezcan o dilaten innecesariamente el trámite.

Por otra parte, en los eventos en que el juez se encuentra frente a la determinación de un posible plagio burdo o literal, puede detectar fácilmente la infracción por cuanto no se trata de un cambio trascendental respecto de la obra prístina, saltando entonces a la vista la cuasi identidad existente entre ambas obras. En este evento, la identificación de una copia literal hace inútil la práctica de la prueba pericial.

Como ejemplo de lo anterior puede hacerse referencia a la sentencia 31403 de 28 de mayo de 2010, donde la Corte Suprema de Justicia de Colombia, Sala de Casación Penal, indicó que en los eventos de plagio burdo o servil, esto es, donde se presentan cambios triviales respecto de palabras o del orden en que se exhibe la creación literaria, deviene en innecesaria la ayuda de expertos, por cuanto el juez, atendiendo a su conocimiento, está en la facultad de contrastar las semejanzas o disparidades de los textos en conflicto ${ }^{63}$.

En consecuencia, la prueba pericial deviene en un medio probatorio idóneo en aquellos casos en que el juez deba acreditar la existencia de un plagio simulado, respecto de una obra que presenta un grado de complejidad proveniente de la forma en que está expresada, sin excluir de plano aquellas obras que se encuentren en un lenguaje mucho más comprensible, pero teniendo en cuenta que el decreto y práctica de la prueba debe seguir los lineamientos del Código General del Proceso.

Asimismo, esos conocimientos especializados o técnicos que posee el auxiliar de justica (perito) le permiten al juez verificar los hechos y guiar su decisión en la declaración de un plagio, respetando en todo caso los derechos sustanciales y procedimentales con que cuentan las partes. En consecuencia, es también obligación del auxiliar de justicia allegar el dictamen de acuerdo a los parámetros de transparencia e imparcialidad que garanticen a su vez los derechos fundamentales del debido proceso, y el derecho de defensa in primis, entre otros.

Finalmente, el dictamen pericial constituye un medio de prueba destinado a proporcionarle al juez los conocimientos necesarios para llevarlo al convencimiento suficiente y razonable de la concurrencia de unos hechos, sin que ello implique que la prueba pericial tenga una fuerza vinculante para el operador judicial, ya que él tiene el deber de analizar el dictamen en conjunto con las demás pruebas, aplicando igualmente las reglas de la sana crítica para formar su propio juicio y fallar en derecho.

63. Corte Suprema de Justicia, Sala de Casación Penal. Sentencia 31403 de 28 de mayo de 2010, M.P.: Sigifredo Espinosa Pérez, en Jurisprudencia y Doctrina n. ${ }^{\circ} 463$, julio de 2010, p. 100. 


\section{Aproximación a los métodos sistemáticos}

APLICADOS EN LA JURISPRUDENCIA DE Estados UNIDOS PARA LA COMPARACIÓN DE OBRAS DE DIFERENTES GÉNEROS

Y LA EVALUACIÓN DE LA SIMILITUD SUSTANCIAL

Como se ha expuesto, el criterio de la similitud sustancial tiene especial relevancia para la correcta valoración del plagio en cualquier tipo de obra con independencia del género al que esta pertenezca.

A continuación se procede a exponer y analizar algunos casos relevantes de la jurisprudencia norteamericana donde la controversia se ha centrado en analizar la existencia y configuración de dicha infracción respecto de algunas creaciones de diferentes géneros, así como el hecho de que los diversos circuitos han establecido varios métodos o criterios de comparación para fines de establecer la similitud sustancial.

La presentación y análisis de casos se efectúa con el objetivo de disponer de herramientas jurídico-legales que permitan definir y proponer un método sistemático para ser implementado y aplicado en Colombia en lo que concierne al análisis del plagio, con especial referencia a la obra cinematográfica.

\section{I. NiChols V. UNIVERSAL PiCtURes CORP. 45 F.2D 119 (2D CiR.) $(1930)^{64}$}

Órgano: Corte de Apelaciones del Segundo Circuito

Fecha: 10 de noviembre de 1930

Demandante: Anne Nichols

Demandado: Universal Pictures Corp.

Juez de Distrito: Learned Hand

\section{Antecedentes}

Anne Nichols demandó a Universal Pictures Corp. por infracción a los derechos de autor, alegando que existía una similitud sustancial entre la obra de teatro Abie's Irish Rose, por ella escrita y que versaba sobre una familia judía residente en Nueva York, y la película The Cohens and Kellys, que Universal había realizado, producido y distribuido. 
Nichols afirmó que la vulneración radicaba en la existencia de estrechas similitudes entre su obra y la película ${ }^{65}$, por cuanto las historias giraban en torno a familias judías, una pareja enamorada que luchaba contra los familiares, presentándose además emociones similares en el desarrollo de ambas obras.

La demandante indicó que para comprobar la existencia de la infracción debían separarse las escenas de la obra de teatro, para así extraer lo importante de cada una comparando las ideas y emociones empleadas, y que si los conceptos, temas emocionales, personajes básicos, etc. eran similares, entonces quedaba demostrada la violación a sus derechos.

\section{Argumentos de la parte demandada 66}

Universal argumentó la existencia de una creación independiente respecto de la obra de Nichols, no siendo en este sentido, válida la afirmación de la demandante sobre una vulneración a sus derechos de autor proveniente de un plagio.

\section{Consideraciones y pronunciamiento del órgano encargado}

La Corte menciona en primer término que la regulación relativa a la infracción y el plagio está claramente definida, pero que en la práctica genera dificultades por cuanto resulta especialmente complejo determinar los puntos precisos donde se genera similitud o disparidad entre dos composiciones dramáticas o de otro género. Asimismo, pone de presente que los conceptos e ideas no se encuentran protegidos per se, siendo solamente la expresión de los mismos lo que merece protección. No obstante, es clara al reconocer que la diferencia entre la idea y la expresión de la misma no siempre es fácil de identificar.

Por otro lado, respecto de la valoración de las escenas solicitada por la demandante para comprobar la existencia de la infracción, la Corte aclara que esta no cumple con los requisitos de una prueba a la luz de la legislación correspondiente y, por ende, no es susceptible de ser aplicada. En este sentido, pone en evidencia que el hecho de que dos obras presenten una misma tendencia respecto de las emociones empleadas no es suficiente para demostrar la existencia del plagio, ya que se trata de meras ideas pertenecientes al dominio público.

65. Cabe precisar que en el presente caso no se indicó que la presunta obra infractora hubiese hecho una apropiación indebida de los diálogos.

66. Law School Case Briefs. Nichols v. Universal Pictures Corp. (2nd Cir.) (1930). 45 F.2d 119. Traducción propia. Disponible en: http://www.invispress.com/law/property/nichols.html Consultado el 6 de mayo de 2015. 
Situación contraria se presenta cuando la comparación radica en todos aquellos elementos empleados para producir una emoción específica, siendo estos los que en realidad son objeto de comparación, ya que pueden existir emociones similares ocasionadas por factores diferentes.

En ese sentido, precisa que para demostrar la violación debe existir una misma secuencia de eventos que ocasionen emociones equivalentes para que la infracción sea evidente, por cuanto la expresión entre obras en conflicto debe coincidir.

Por otro lado, se advierte la diferencia entre los dos tipos de infracción: en el primer caso, la que se refiere a la apropiación literal de otra obra, caso en el cual la infracción es evidente; y en el segundo, la referida a la situación en que el plagiador no toma tal cual una parte de la otra obra, sino que efectúa un resumen de la totalidad de esa creación. En este último evento debe acudirse a analizar la similitud sustancial entre las obras, ya que la comparación se torna compleja ${ }^{67}$.

Asimismo, se destaca que cuando el conflicto se refiere a obras de teatro, el plagiador puede, por ejemplo, extirpar una escena separada o bien apropiarse de una porción del diálogo, por lo que la pregunta a responder en estos casos es si la parte empleada es sustancial y su uso no se encuentra dentro de un fair use'. A la luz de lo anterior debe recurrirse a una serie de abstracciones teniendo en cuenta que deben eliminarse de la comparación todos aquellos elementos generales, para poder establecer cuáles son los que están dotados de originalidad y son verdaderamente tutelados por el derecho de autor. Lo anterior, por cuanto un dramaturgo no puede impedir el uso de sus "ideas", ya que se crearía un monopolio injustificado.

En consecuencia, deben como primera medida excluirse del análisis todos aquellos elementos generales no susceptibles de protección, para así verificar si la similitud sustancial radica en los elementos esenciales de la obra.

Por ende, el derecho de autor permite que se exploten los hechos, experiencias e ideas generales, siempre que no se presente copia sustancial de la forma concreta en que se han desarrollado. Así, si bien en el presente caso ambas obras se valen de elementos comunes (personajes judíos e irlandeses, la unión en matrimonio de dos personas pese a la oposición de sus padres, la reconciliación de los personajes), estos no son fundamento válido para declarar la existencia de plagio, máxime cuando el desarrollo de las historias presentadas es muy diferentes, tal y como se muestra a continuación.

67. Corte de Apelaciones del Segundo Circuito de Estados Unidos. Nichols v. Universal Pictures Corporation. Disponible en: http://digital-law-online.info/cases/7pq84.htm Consultado el 6 de mayo de 2015. 


\begin{tabular}{|c|c|}
\hline Abie's Irish Rose & The Cohens and Kellys \\
\hline e & \\
\hline Aspectos comunes & Aspectos comunes \\
\hline Cuatro personajes principales: & Cuatro personajes principales: \\
\hline $\begin{array}{l}\text { - Los judíos: el padre (Solomon LeVy) y el } \\
\text { hijo (АвIE) }\end{array}$ & $\begin{array}{l}\text { - Los judíos: el padre (Nathan Cohen) y la } \\
\text { hija (NANNIE COHEN) }\end{array}$ \\
\hline $\begin{array}{l}\text { - Los católicos: el padre (Murphy) y la hija } \\
\text { (RosEMARY) }\end{array}$ & $\begin{array}{l}\text { - Los católicos: el padre (Kelly) y el hijo } \\
\text { (TerRY) }\end{array}$ \\
\hline $\begin{array}{l}\text { - Corresponden a prototipos presentes en } \\
\text { décadas }\end{array}$ & $\begin{array}{l}\text { - Corresponden a prototipos presentes en } \\
\text { décadas }\end{array}$ \\
\hline $\begin{array}{l}\text { Matrimonio secreto entre los jóvenes, por el } \\
\text { prejuicio de los padres. }\end{array}$ & $\begin{array}{l}\text { Matrimonio secreto entre los jóvenes, por el } \\
\text { prejuicio de los padres. }\end{array}$ \\
\hline $\begin{array}{l}\text { Distanciamiento de los jóvenes de sus padres } \\
\text { por decisión de estos. }\end{array}$ & Distanciamiento del padre y la hija. \\
\hline $\begin{array}{l}\text { Emociones comunes: } \\
\text { - Amor e ira. }\end{array}$ & $\begin{array}{l}\text { Emociones comunes: } \\
\text { - Amor e ira. }\end{array}$ \\
\hline $\begin{array}{l}\text { Cualidades de la figura paterna: cariñosa, } \\
\text { cálida y patriarcal. }\end{array}$ & $\begin{array}{l}\text { Cualidades de la figura paterna: grotesca, } \\
\text { extravagante y pendenciera. }\end{array}$ \\
\hline Aspectos disimiles & Aspectos disimiles \\
\hline $\begin{array}{l}\text { La religión: es una característica predominante } \\
\text { de la obra. }\end{array}$ & $\begin{array}{l}\text { La religión: si bien los personajes pertenecen } \\
\text { a una religión, no es una dimensión predo }\end{array}$ \\
\hline
\end{tabular}

68. Abie's Irish Rose (imagen). Meridian Gallery-Art \& Design, Truth, Beauty and the power of Ornamentation. Disponible en: http://meridiangallery.blogspot.com/2014/06/ nancy-carroll-1903-1965-what-sweetie.html Consultado el 6 de mayo de 2015.

69. The Cohens \& Kelly's (imagen). Copyright in a Global Information Economy, 


\begin{tabular}{|c|c|}
\hline Temas tratados: & Temas tratados: \\
\hline $\begin{array}{l}\text { - Odio entre judíos e irlandeses, desde tiempos } \\
\text { inmemorables. }\end{array}$ & - Disputas familiares. \\
\hline $\begin{array}{l}\text { - Amor de un padre por su hijo y el deseo de } \\
\text { este por garantizar su descendencia. }\end{array}$ & - El materialismo superado por la integridad. \\
\hline Reconciliación: & Reconciliación: \\
\hline - El amor paternal hacia los nietos (gemelos) & - La honestidad y el sentido de justicia de uno \\
\hline de los personajes genera la reconciliación. & $\begin{array}{l}\text { de los personajes como medio para la recon- } \\
\text { ciliación, al devolver la herencia a quien era } \\
\text { su verdadero titular. }\end{array}$ \\
\hline $\begin{array}{l}\text { Personajes secundarios: un rabino y un padre } \\
\text { católico. }\end{array}$ & $\begin{array}{l}\text { Personajes secundarios: un abogado que le } \\
\text { informa a Cohen que ha obtenido una heren- } \\
\text { cia, pero luego se descubre que le pertenece } \\
\text { a Kelly. }\end{array}$ \\
\hline Los padres no se conocen. & Los padres son enemigos de tiempo atrás. \\
\hline
\end{tabular}

Test empleado por el órgano encargado para fundamentar su decisión

\section{"Abstraction Test" o "Test de Abstracción"}

Como primer paso debe demostrarse la existencia de "la titularidad de la obra que se alega como infringida y el acceso que frente a la misma el demandado pudo haber tenido" 70 .

Posteriormente se establece una línea recta, donde en un extremo se indica el concepto como tal y en el otro su expresión. De esa manera y a medida que la historia contenga más detalles y secuencias concatenadas de eventos, se convierte en un relato más complejo, haciendo más difícil resumir la totalidad de la obra, por lo que la similitud se evidencia a partir de la existencia de esos pormenores; mientras más semejanza haya, más factible se hace determinar la vulneración de los derechos que detenta el autor o creador ${ }^{71}$.

De esta forma, los niveles de abstracción a analizar, en orden descendente, son $^{72}$ :

Chapter 5. Disponible en: http://www.coolcopyright.com/cases/chp5/nicholsuniversal.htm Consultado el 6 de mayo de 2015.

70. Castellanos, ob. cit., p. 46.

71. Tobón Franco, Natalia y Varela Pezzano, Eduardo. Derecho de autor para creativos. Bogotá, Grupo Editorial Ibáñez, 2010, pp. 123-124.

72. Copyright Infringement II, Intro to IP - Prof Merges. 2.23.09. Berkeley Law. 
- Idea principal de la historia

- Argumento

- Sub argumentos

- Personajes generales y escenas

- Personajes y escenas específicas

- Texto

\section{Decisión del órgano encargado}

Una obra construida sobre la base de conflictos entre irlandeses y judíos, el matrimonio secreto entre los hijos de estos, y un final feliz luego de una reconciliación, no es fundamento admitido para la protección autoral. Por lo tanto, no existe vulneración por parte de Universal Corp., ya que si bien se evidencian elementos similares, estos corresponden a temas de popularidad duradera pertenecientes al dominio público y, en suma, inapropiables.

Aunque la obra Abie's Irish Rose fue exitosa y podría considerarse original en cuanto a la forma en que fue exteriorizada y representada al público, no se puede predicar sobre las ideas un monopolio de exclusividad.

\section{Comentario}

Esta sentencia presenta el "Test de Abstracción", que permite establecer la existencia de una similitud sustancial entre obras eliminando del examen todos aquellos elementos no susceptibles de protección; en esa medida, se observa que la Corte hace un esfuerzo por diferenciar la expresión, protegible, de los simples conceptos.

Asimismo, aplica el principio universal en materia de derecho de autor, donde la idea no es protegible en sí misma, siéndolo solo su forma de expresión, por lo que cualquier persona puede usar contenidos de dominio público para crear una expresión singular: es esta la que verdaderamente es salvaguardada y sobre la que debe versar el análisis en la determinación de un plagio.

De esta forma, pese a que existen semejanzas entre las obras en conflicto, si las mismas se basan en contenidos o elementos no susceptibles de protección no se configura el plagio.

Finalmente, vale la pena destacar que esta sentencia fue muy influyente para casos posteriores, por cuanto muestra de manera esquematizada ciertos niveles de abstracción que permiten guiar el análisis para fines de excluir los elementos accesorios y no susceptibles de tutela y de exponer la similitud existente entre las obras. 
5.2. Roth GREETING CARDS V. UNITED CARD COMPANY, 429 F. 2 D 1106 (9TH CIR. 1970) ${ }^{73}$

Órgano: Corte de Apelaciones del Noveno Circuito

Fecha: 10 de julio de 1970

Demandante: Roth Greeting Cards

Demandado: United Card Company

Juez de Circuito: Koelsch y Kilkenny

\section{Antecedentes y argumentos de la parte demandante}

Roth Greeting Cards y United Card Company eran compañías dedicadas a la venta de tarjetas con mensajes y diseños alusivos a una fecha especial o que transmitían alguna felicitación.

Roth Greeting Cards encontró que, su competencia United Card Company tenía dentro de su portafolio de tarjetas, siete credenciales con un estrecho parecido a las que él comercializaba, razón por la cual, interpuso demanda alegando infracción a sus derechos de autor, por cuanto afirmó que, "la disposición de las palabras, la combinación, el esquema y el arte empleado era original y debía ser protegido por la legislación autoral"74, respecto de la vulneración realizada por el que sería el demandado en el caso.

\section{Argumentos de la parte demandada}

United Card Company afirmó que, no existía un derecho de autor sobre las tarjetas de Roth y en esa medida no se configuraba la infracción alegada.

En igual sentido, se indicó que el vicepresidente de la compañía había tenido múltiples ideas para los diseños de las tarjetas por cuanto, había visitado varias tiendas donde se encontraban diversos tipos de credenciales con el fin de observar que era lo que estaba en boga en ese momento, así como se guió por las ideas de su personal, sus amigos, etc., pero admitió que él durante esas visitas podía haber visto las de su competidor antes de realizar sus postales.

73. Corte de Apelaciones del Noveno Circuito de Estados Unidos. Roth Greeting Cards v. United Card Company (9th Cir.) (1970). 429 F.2d 1106 Judge. Hamley. Traducción propia. Disponible en: http://scholar.google.ca/scholar_case?case $=4616368592376161797 \& \mathrm{~h}$ $\mathrm{l}=$ en\&as_sdt $=2 \&$ as_vis $=1 \& o i=$ scholarr\&sa $=X \&$ ei $=$ NAvnT6f1 FqnM2AX66IzaCQ\&ved $=0$ CB gQgAMoADAA Consultado el 6 de mayo de 2015; Law School Case Briefs. Roth Greeting Cards v. United Card Co. 429 F.2d 1106 (9th Cir. 1970). Traducción propia. Disponible en: http://www.invispress.com/law/copyright/roth.html Consultado el 6 de mayo de 2015.

74. "Roth argues that 'II]t is the arrangement of the words, their combination and plan, together with the appropriate art work' which is original, the creation of Roth, and entitled to copyright protection": en Corte de Apelaciones del Noveno Circuito de Estados Unidos. Roth Greeting Cards v. United Card Company, cit. 


\section{Decisión en primera instancia}

La primera instancia indicó una falta de jurisdicción para resolver el caso por cuanto, el demandante no había cumplido con todas las formalidades para el reconocimiento de sus derechos de conformidad con el registro y depósito de las obras ${ }^{75}$.

Por otro lado, respecto de la cuestión de fondo indicó que si bien las tarjetas estaban protegidas por el derecho de autor, no se presentaba una vulneración aunque se hubiera dado la copia de los textos y palabras, ya que estos eran carentes de protección por encontrarse en el dominio público y en consecuencia, no estaban dotados del requisito esencial de la originalidad.

\section{Consideraciones y pronunciamiento del órgano encargado}

El Circuito expresa que, para evidenciar la infracción debe existir una similitud sustancial entre la obra infractora y la afectada y que esa semejanza debe provenir de la copia de esta última. Por lo cual, debe tenerse en cuenta: 1 . La prueba de acceso, y 2. La similitud sustancial.

Sin embargo, se señala que una excepción respecto de la presunta vulneración puede ser la creación independiente.

En igual sentido, advierte que las tarjetas deben ser consideradas en su conjunto como un todo o unidad y en este sentido, al estudiar la disposición de las palabras, la combinación de las mismas, ligado con el esquema y el arte empleado, éstas cumplen con el requisito de la originalidad siendo susceptibles de ser salvaguardadas.

De esta manera, si bien se reconoce que el Derecho de Autor no protege las ideas, si es dable proteger su expresión tangible razón por la cual, las tarjetas de felicitaciones al ser manifestaciones concretas de diferentes conceptos como el humor, la alabanza, el arrepentimiento, etc., son objeto de tutela.

Asimismo, se hace énfasis en que la similitud sustancial entre obras en conflicto, se da en los eventos en que el acusado copia elementos fundamentales de la creación protegida y no respecto de meras coincidencias.

75. Código de los Estados Unidos de América. Título 17, Ley de Copyright. United States Code Title $17 \$ 10,13$ and 209. Disponible en: http://www.bitlaw.com/source/15usc/1125. html Consultado el 6 de mayo de 2015. 
Test empleado por el órgano encargado para fundamentar su decisión

"The Total Concept and Feel Test" o "Test del concepto y de sensación total"

Test de carácter subjetivo donde se evalúa si el concepto y el tono o la sensación de las obras en conflicto resulta sustancialmente similar en función de lo que establezca el "observador promedio".

Vale la pena destacar que en el presente caso no se consideraron medios de prueba sino que se examinaron las tarjetas de felicitaciones y se tomó una decisión basada en ${ }^{76}$ :

- Los personajes dibujados

- El estado de ánimo representado en las tarjetas

- La combinación de la representación de un estado de ánimo particular con un mensaje singular para la situación

- La disposición de las palabras en las tarjetas de felicitaciones

- En varios casos, la tipografía de las expresiones

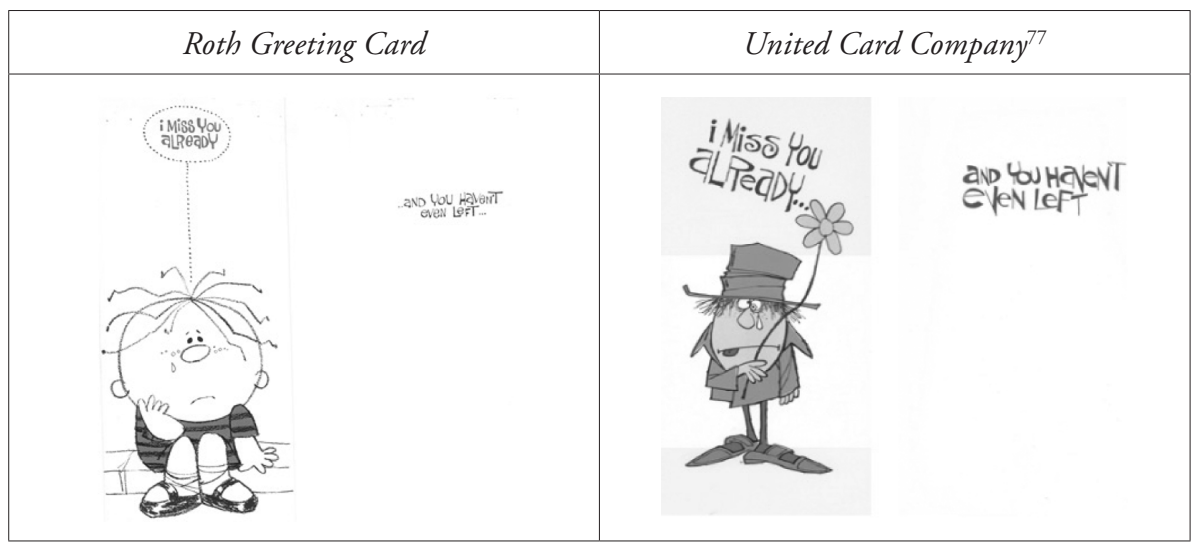

76. "It appears to us that in total concept and feel the cards of United are the same as the copyrighted cards of Roth. With the possible exception of one United card (exhibit 6), the characters depicted in the art work, the mood they portrayed, the combination of art work conveying a particular mood with a particular message, and the arrangement of the words on the greeting card are substantially the same as in Roth's cards. In several instances the lettering is also very similar": Corte de Apelaciones del Noveno Circuito de Estados Unidos. Roth Greeting Cards v. United Card Company, cit.

77. Boston College Law School. Intellectual Property. Copyright-Ownership, Duration. January 18, 2008 (imágenes, presentación de Power Point), p. 4. Disponible en: https:// www2.bc.edu/ liujr/courses/ip08s/powerpoint/c05-c-ownership.ppt Consultado el 6 de mayo de 2015. 


\section{Decisión del órgano encargado}

Las tarjetas en cuestión presentan una estrecha similitud incluso para un "observador casual", por lo cual, al no haberse refutado el acceso que tuvo United respecto de las credenciales de su competencia, y sumado a la marcada semejanza existente entre las mismas, el tribunal llega al convencimiento de que las postales del demandado son una copia de las de Roth, y en ese sentido se configura una infracción respecto de los derechos de autor que ostenta la demandante.

Finalmente y con base en la disposición de las palabras, su combinación y esquema, junto al arte aplicado, se reconoce protección a las tarjetas de felicitaciones de la empresa Roth, por cuanto al aplicar "The Total Concept and Feel Test" se evidencia que las credenciales de uno y otro generan la misma impresión, y en ese sentido hasta un observador promedio, e incluso uno casual, está en condiciones de establecer que las postales infractoras tomaron sin autorización los elementos protegidos de la creación prístina.

\section{Comentarios}

Como se puede observar, el test aplicado en este caso es de carácter subjetivo, por cuanto se basa en las impresiones de aquellos que comparan las tarjetas, mas no se realiza una distinción rigurosa entre los elementos no susceptibles de protección y aquellos protegidos efectivamente por la legislación autoral.

La impresión del observador puede variar, razón por la cual no en todos los casos es viable advertir la existencia de una similitud sustancial que sea suficente para fundamentar una sentencia favorable para el presuntamente afectado.

En este evento, a diferencia de otros casos que son expuestos en este acápite, el "concept and feel" es de aplicación pura y no como un elemento a tener en cuenta dentro del análisis, como se verá más adelante en el caso Sid \& Marty Krofft Television Productions., Inc. v. McDonald's Corp.

Si bien es cierto que las ideas en sí mismas no se encuentran protegidas, su expresión tangible sí; sin embargo, en el presente caso la Corte al parecer fue mucho más allá, al no tener en cuenta elementos objetivos dentro del estudio que permitieran evidenciar la existencia o no de una infracción. Dicha falencia objetiva puede deberse a que el test aplicado no presenta una etapa en el estudio que elimine de la comparación aquellos contenidos de dominio público o que carecen de protección con el fin de analizar los aspectos fundamentales de la creación intelectual salvaguardada.

Se puede entonces concluir que el presente test alude más a impresiones subjetivas y respuestas emocionales que no permiten discernir de manera lógica y racional la existencia de un plagio por parte del presuntamente infractor, por lo cual es viable adherirse en este caso a la disidencia manifestada por el juez KiLKenny. 
5.3. Sid \& MARTY KROFFT TELEVISION PRODUCTIONS., INC. V. MCDONALD'S CORP. 562 F.2D 1157 (9 $^{T H}$ CIR. 1977) ${ }^{78}$

Órgano: Corte de Apelaciones del Noveno Circuito

Fecha: 12 de octubre de 1977

Demandante: Sid \& Marty Krofft

Demandado: McDonald's Corp.

Juez de Distrito: Carter, Goodwin y Sneed

\section{Antecedentes}

Sid \& Marty Krofft demandaron a McDonald's Corp. por infracción a los derechos de autor, alegando que existía una similitud sustancial entre el programa de televisión infantil HR Pufnstuf, que había sido creado por ellos y producido para la cadena de televisión NBC, y la campaña publicitaria "Mcdonaldland", desarrollada por la agencia de publicidad Needham, Harper y Steers para la cadena de comidas rápidas.

En 1968 la NBC contrató a Sid y Marty Krofft para que crearan un programa de televisión dirigido al público infantil, dada la reputación de sus shows, donde se manejaban títeres, y un año después la serie HR Pufnstufse estrenó los sábados en la mañana en ese canal. Este programa se basaba en la vida después del naufragio de un niño llamado "Jimmy", en la isla "Living Island", un lugar de fantasía donde los árboles y los libros eran parlantes, y el alcalde de la isla era un dragón llamado "HR Pufnstuf", quien protegía a Jimmy de "la bruja Wilhelmina", principal antagonista. La serie de televisión se hizo muy popular y generó toda clase de productos promocionales.

78. Corte de Apelaciones del Noveno Circuito de Estados Unidos. Sid \& Marty Krofft Television Productions, Inc. v. McDonald's Corporation and Needham, Harper \& Steers, Inc. (9th Cir.) (1977) 562 F. 2d 1157196 U.S.P.Q. 97 Judge Carter. Traducción propia. Disponible en: https://law.resource.org/pub/us/case/reporter/F2/562/562.F2d.1157.75-1202.75-1203. html, http://law.justia.com/cases/federal/appellate-courts/F2/562/1157/293262/, http:// www.studentweb.law.ttu.edu/Cochran/Cases\%20\&\%20Readings/Copyright-UNT/krofft.htm Consultado el 06 de mayo de 2015; Law School Case Briefs. Sid \& Marty Krofft Television Productions, Inc. v. McDonald's Corporation and Needham, Harper \& Steers, Inc. 562 F. 2d 1157 (9th Cir. 1977). Traducción propia. Disponible en: http://www.invispress.com/law/ copyright/krofft.html Consultado el 6 de mayo de 2015; Sid \& Marty Krofft Television Productions, Inc. v. McDonald's Corp. (9th Cir. 1977). 562 F.2d 1157. Copyright in a Global Information Economy, Chapter 5. Traducción propia. Disponible en: http://www. coolcopyright.com/cases/chp5/kroftmcdonalds.htm Consultado el 6 de mayo de 2015; Krofft v. McDonald's-9th Cir. 1977-Copyright in Hamburgler and Mayor McCheese. Substantial Similarity. July 9, 2013. Traducción propia. Disponible en: http://www.copyrightcodex. com/tag/substantial-similarity Consultado el 6 de mayo de 2015. 
Posteriormente, en 1970, un ejecutivo de la agencia de publicidad Needham, Harper y Steers se puso en contacto con los Krofft con el fin de que colaboraran en una campaña publicitaria para McDonald's basados en la serie de televisión, por lo que, después de varias conversaciones y ya avanzado el proyecto, el ejecutivo les indicó que el mismo había sido cancelado. Sin embargo, la agencia ya había sido seleccionada para realizar la campaña denominada "Mcdonaldland", y se había contratado a los empleados de los Kroffts para que diseñaran y construyeran los trajes, así como al mismo experto de las voces del programa para que les diera vida a los personajes.

Esta situación ocasionó que, los demandantes no pudieran obtener nuevos acuerdos de licencia de uso de los personajes de la serie siendo incluso reemplazados por los personajes de la campaña para McDonald's.

\section{Argumentos de la parte demandante}

Sid y Marty Krofft presentaron demanda contra la agencia de publicidad y la cadena de restaurantes de comida rápida alegando la vulneración a los derechos de autor sobre la serie de televisión y de algunos artículos de merchandising, por cuanto según ellos existía una similitud sustancial entre la obra protegida y la campaña publicitaria infractora. Asimismo, se solicitó el reconocimiento de us\$ 250.000 como resarcimiento por los daños ocasionados y, en subsidio, un reconocimiento en función de las ganancias obtenidas por el infractor.

\section{Argumentos de la parte demandada ${ }^{79}$}

Los acusados manifestaron que sus anuncios televisivos no vulneraban la serie de televisión y que, en caso de declararse la infracción, esa decisión iría en detrimento de los derechos que tenían de conformidad con la Primera Enmienda. Igualmente, refutaron el argumento de la parte demandante acerca de los daños y perjuicios alegados.

\section{Decisión en primera instancia}

Se reconoció el pago de daños derivados de la infracción a los derechos de autor en favor de la parte afectada por un monto inferior al solicitado, concediéndoseles solo us \$ 50.000. Sin embargo, la parte demandante alegó su derecho a obtener una compensación monetaria adicional, situación que llevó a que ambos interpusieran recurso de apelación.

79. Sid \& Marty Krofft Television Productions, Inc. v. McDonald's Corporation and Needham, Harper \& Steers, Inc., cit. 


\section{Consideraciones y pronunciamiento del órgano encargado}

En primer término, la Corte señala que en este tipo de casos debe precisarse si se ha producido una copia de la expresión de una idea y no de la idea en sí misma. De esta manera, hace alusión al "test de abstracción" del juez Hand, estudiado de manera previa, así como manifiesta que para establecer la infracción es necesario verificar, primero, que efectivamente existe un derecho de autor que proteger, y segundo, el acceso del infractor a la obra prístina presuntamente afectada.

Subsecuente a esto, debe observarse si existe una semejanza esencial no solamente de las ideas generales sino de las expresiones concretas. Por lo cual deben realizarse dos pasos dentro del proceso analítico en el estudio de la similitud sustancial (prueba dual).

Asimismo, aclara que la similitud sustancial es una cuestión de hecho que debe ser analizada en cada caso particular, y enfatiza que solamente puede existir infracción cuando la copia llega hasta el punto de la apropiación indebida de la expresión protegida y no es una mera reproducción del concepto.

En este sentido, se hace referencia a que si bien McDonald's no refuta el hecho de haber copiado la idea de la serie de televisión caracterizada por la existencia de un mundo de fantasía y personajes extravagantes, el análisis al que alude la demandada, según ella, debe hacerse con miras a verificar las diferencias entre las expresiones para poder probar que no existe vulneración alguna.

Sin embargo, sobre este argumento la Corte es clara en precisar que la determinación de la infracción no se puede hacer a partir de las diferencias existentes entre las creaciones sino que, por el contrario, el criterio de la similitud sustancial debe atender a las semejanzas, ya que de no ser así la infracción no es expuesta, por cuanto bajo esta perspectiva no se tendría en cuenta la dicotomía entre la idea y la expresión, siendo entonces la aplicación de la prueba extrínseca inadecuada (primer paso del test).

Igualmente, la Corte hace énfasis en que se debe tener en cuenta dentro del test intrínseco al público destinatario de las obras, ya que en este caso las mismas tienen un impacto particular en el público infantil.

De esta manera, la prueba aplicada para evidenciar la vulneración ha de incluir a un observador promedio, que en este caso son los niños, porque al ver estos las creaciones desearán adquirir los productos que ofrece la campaña, sin detenerse a contemplar los detalles diferentes de cada uno (cuello de los personajes, vestimenta, aspecto, etc.); situación que resulta relevante y no puede dejarse de lado, más cuando McDonald's, reconociendo la popularidad de la serie entre los niños, optó por recrear el formato del programa de televisión HR Pufnstuf, en lugar de utilizar un enfoque distinto y dotado de originalidad para realizar su campaña. 
Test empleado por el órgano encargado para fundamentar su decisión

\section{"Extrinsic Test-Instrinsic Test" o "Test Extrinseco y Test Intrínseco"}

Para establecer la existencia de una similitud sustancial entre obras en conflicto debe hacerse un análisis dividido en dos etapas con el fin de declarar la existencia de una infracción. De esta manera se presenta una prueba dual en el proceso de detección del plagio, como se explica a continuación.

\section{- Test Extrínseco}

Corresponde a una "evaluación objetiva que se focaliza en las similitudes entre el esquema, tema, diálogo, ánimo, ambientación, ritmo, personajes y secuencia de eventos, detectando todos los elementos comunes entre las dos obras. De dichos elementos deben descartarse los elementos no protegibles, es decir las escenas que surgen naturalmente de las premisas de la trama básica, elementos comunes a otros programas anteriores, y elementos comunes que hayan surgido de la llamada "herencia directa" o "fenómeno de impregnación". Así, pues, si se satisfacen los requisitos de la prueba extrínseca, se realiza finalmente la prueba intrínseca ${ }^{80}$.

Este primer paso en la prueba dual es de carácter objetivo ya que el juez no debe realizar apreciaciones subjetivas, sino que filtra y distingue todos aquellos elementos de una creación que son o no objeto de protección. Así, se indica como primer paso en la realización de un examen extrínseco la identificación clara de los tipos de obras en conflicto, para después entrar a analizar los elementos mencionados en el párrafo anterior, correspondientes al esquema, tema y ambientación, entre otros ${ }^{81}$.

Asimismo, vale la pena hacer alusión a que en esta fase, aparte del análisis de estos elementos, la prueba de expertos ${ }^{82}$ cobra especial relevancia, por cuanto en esta primera etapa, al ser de carácter objetivo, la ayuda de un auxiliar dotado de conocimientos especiales resulta fundamental pues permite orientar al juzgador

80. Antequera Parilli, Ricardo. Plagio. Apreciación. Programa de televisión. Formato. Uso de elementos comunes. Rechazo. Argentina. Cámara Nacional de Apelaciones en lo Civil, Sala D. 12 de febrero de 2009. Jurisdicción Judicial (civil). Texto del fallo en formato digital. Paz, Teodosio Luis vs. Asociación Argentina de Televisión por Cable A.T.V.C. En: Centro Regional para el Fomento del Libro en América Latina y El Caribe, Cerlalc, p. 12. Disponible en: (http://www.cerlalc.org/derechoenlinea/dar/index. php? mode=info\&id=2031 Consultado el 6 de mayo de 2015.

81. Es importante aclarar que, hasta este momento no se tomaban dichos elementos como objetivos dentro de la valoración, situación que cambia con el caso de Shaw v. Lindheim.

82. Sid \& Marty Krofft Television Productions, Inc. v. McDonald's Corporation and Needham, Harper \& Steers, Inc., cit. 
a la hora de precisar cuáles elementos están dotados del requisito esencial de la originalidad y cuáles no.

Habida cuenta de lo anterior, es igualmente importante referirse a grandes rasgos a dos tipos de doctrinas que se aplican en esta fase, ya que permiten descartar del análisis aquellos elementos que no son protegibles por la vía autoral y que le permiten al juzgador "delimitar, filtrar y distinguir los niveles de abstracción y protección merecida, respecto de cada uno de los elementos involucrados dentro de la arquitectura tangible y conceptual, respectivamente, de una determinada obra literaria, artística o científica" ${ }^{\text {83-84. }}$

\section{a. "Merger Doctrine" o Doctrina de la Convergencia ${ }^{85}$}

Esta doctrina alude al evento en que la expresión de una idea es limitada y esta y su manifestación formal son inseparables, por lo que, pese a su originalidad, el derecho de autor no puede protegerla, pues en tal caso crearía un monopolio de exclusividad, yendo en detrimento de terceros que deseen emplear el mismo concepto. En este sentido, Carlos Castellanos advierte:

La doctrina de la convergencia no sólo reduce los riesgos de error de las cortes cuando de determinar los niveles de abstracción de cada uno de los elementos involucrados dentro de la arquitectura tangible de una determinada obra se trata sino que, a su vez, niega protección vía Copyright en casos donde existe solamente un número limitado de opciones de expresión, convirtiéndose así en una valiosa herramienta analítica para las cortes en el difícil proceso de definir, ad hoc, las fronteras entre la expresión protegible y las ideas no protegibles ${ }^{86}$.

83. Castellanos, ob. cit., p. 50.

84. Ibíd., p. 48, notas 49 y 50. El autor anteriormente mencionado señala: "por arquitectura tangible de la obra entenderemos las partes literarias que explícitamente se perciben de una obra". En este grupo se encuentran, por ejemplo: las letras del alfabeto; las palabras, frases, signos de puntuación, párrafos, páginas, capítulos, libros, combinación de colores, símbolos, diagramas, títulos, dialectos técnicos, descripciones, trazados, entre otros. Y por arquitectura conceptual, "las partes no tangibles que se involucran en el tratamiento y desarrollo de una determinada obra. En este grupo se encuentran, por ejemplo: un género, una trama específica, incidentes, personajes o escenarios que son estándares al tratamiento de una determinada temática, una historia, aspectos funcionales y técnicos que pueden no dictar el desarrollo de una determinada obra, entre otros".

85. Para ejemplos de esta doctrina cfr.: Herbert Rosenthal Jewelry Corp. v. Kalpakian, 446 F. 2 d 738 (9th. Cir 1971); Morrisey v. Procter and Gamble Co. 379 F.2d 675 (1st Cir. 1967).

86. Castellanos, ob. cit., pp. 52-53. 


\section{b. Doctrina del "Scénes à faire" o escenas que deben ser hechas ${ }^{87}$}

Esta doctrina alude a la identificación de aquellos elementos estándar que por el carácter de la obra no pueden ser protegidos por la legislación autoral, por cuanto corresponden a situaciones connaturales de un tema específico o género, o bien corresponden a aquellas secuencias de eventos que necesariamente tienen lugar en situaciones idénticas; en consecuencia, todos aquellos eventos típicos de una historia común deben ser descartados del análisis.

Por ejemplo, en las películas de terror del subgénero zombi, como La noche de los muertos vivientes, Exterminio, Resident Evil, Guerra Mundial Z, entre otras, los elementos estándar presentes son: sustancias radiactivas o virus que ocasionan que las personas se conviertan en muertos vivientes; zombis que buscan matar, morder o destrozar a cualquier humano que se encuentren; la infección que los transforma rápidamente a ese estado; el personaje que descubre que los muertos desean acabar con todo a su paso; la lucha de un líder para encontrar una cura o la forma de matarlos; etc. Así, todos estos elementos comunes al género se encuentran fuera de la esfera de protección del derecho de autor y no es posible reclamar sobre los mismos amparo alguno.

\section{- Test Intrínseco}

Este segundo paso solo se realiza si después de haber practicado la prueba extrínseca se han revelado similitudes en el tema, diálogo, ambientación, etc. En esta fase el estudio no depende de criterios y análisis externos presentes en el Test Extrínseco, sino que se realiza una evaluación puramente subjetiva acerca de si "el concepto y el tono o sensación” de las dos obras son sustancialmente similares, en función de la respuesta de un observador promedio al comparar las creaciones en conflicto.

En este caso, el juzgador de los hechos revisa las obras y toma una decisión en cuanto a si ellos son sustancialmente similares o no ${ }^{88}$. De esta manera, puede indicarse que esta fase:

Es más exhaustiva ya que se determinan las similitudes que van más allá de las necesidades del tema y descartan la posibilidad de "accidente literario". La prueba intrínseca consiste en cotejar las dos creaciones como un todo y no desviando la atención solamente en las coincidencias existentes (elementos extrínsecos) con el fin de determinar si las dos obras son substancialmente similares a los ojos de un observador promedio ${ }^{89}$.

87. Sobre el origen de esta teoría, cfr. Cain v. Universal Pictures Co., 47 F. Supp. 1013 (S.D.Cal. 1942).

88. Osterberg y Osterberg, ob. cit., pp. 3-22.

89. Antequera Parilli. Plagio. Apreciación. Programa de televisión. Formato. Uso de elementos comunes. Rechazo, cit. 


\section{Decisión del órgano encargado}

En consonancia con lo expuesto, puede decirse que los pasos realizados por la Corte para establecer la infracción son:

- Determinar que existe un derecho de autor: Sid y Marty Krofft crearon la serie de televisión HR Pufnstuf, producida para la NBC.

- Determinar el acceso del infractor a la obra: la agencia publicitaria estuvo en contacto permanente con los Krofft para llevar a cabo la campaña con los personajes de la serie de televisión HR Pufnstuf en un primer momento.

- Aplicar test extrínseco: sobre este punto los demandados nunca negaron la copia de la idea de la serie de televisión, situación que ayudó a la Corte en esta etapa. Así como en primera instancia se determinó que las obras en conflicto correspondían a una serie de televisión y a una campaña publicitaria, y posteriormente se realizó una evaluación objetiva de los elementos protegibles que permitiera pasar al siguiente paso.

- Aplicar test intrínseco: la campaña publicitaria es sustancialmente similar a la serie de televisión, por cuanto capturó el "concept and feel”, ya que, teniendo en cuenta que la serie de televisión fue muy popular, el observador promedio (los niños) buscará adquirir los muñecos de la campaña de "McDonaldland", pues estos crean la misma impresión que los de HR Pufnstuf, y en este sentido, entusiasmados por conseguir dichos artículos de la cadena de comidas rápidas, no podrán detectar las diferencias o evidenciar fácilmente aquellos detalles que los distinguen de los muñecos de la serie y de la campaña.

En consecuencia, del análisis de las dos creaciones se evidencian similitudes sustanciales que permiten establecer la toma de ese concepto y sensación o tono de la serie, como por ejemplo:

- “Living Island” y "McDonaldland” son mundos imaginarios habitados por creaturas de fantasía.

- En ambos existen plantas y animales antropomórficos parlantes.

- Las características topográficas dominantes son las mismas, por cuanto usan árboles, cuevas, un estanque, un camino y un castillo.

- Ambas obras presentan científicos locos sorprendentemente similares y una criatura malvada con múltiples brazos.

- En ambas existen alcaldes con cabezas desproporcionadamente grandes y con una anatomía particular caracterizada por bocas anchas y largas, que son asistidos por unos policías. 


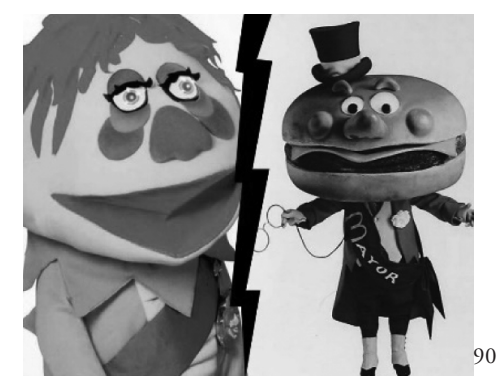

Para finalizar, la Corte concluye que las similitudes existentes entre el programa de televisión y la campaña publicitaria van más allá de meros conceptos, siendo las expresiones de esa idea sustancialmente semejantes. Por lo cual dictamina que McDonald's, aprovechándose del éxito de la serie, recreó el formato de la misma realizando una apropiación indebida, infringiendo por esa vía los derechos de autor que Sid y Martin Krofft ostentaban respecto de HR Pufnstuf. Asimismo y respecto de la indemnización, se estableció un monto mayor que el concedido inicialmente partiendo del cálculo de los "statutory damages", por cuanto no se pudieron medir los beneficios obtenidos por la cadena de restaurantes; en razón de ello se tomaron los artículos promocionales como una sola infracción a nivel global y no de manera singular.

\section{Comentario}

En este caso se presenta un test o prueba más elaborada, dividida en dos pasos, siguiendo un orden lógico para constatar la similitud sustancial. Dentro de esa prueba dual se evidencia la aplicación de doctrinas propias de la jurisprudencia norteamericana, para eliminar del examen aquellos contenidos no susceptibles de protección por la legislación autoral.

Puede observarse que la "Merger Doctrine" y la doctrina de "Scénes à Faire" cobran especial relevancia en la etapa extrínseca, así como la prueba de expertos es de gran relevancia en esta fase del análisis.

Del mismo modo, la etapa intrínseca incluye el criterio del observador promedio que había sido aplicado en casos anteriores pero no en una prueba de dos pasos, lo que permite esquematizar de una manera más organizada, una vez descartados los elementos no protegibles, la existencia de una similitud sustancial entre las obras que deriva en la existencia de un plagio.

90. The evolution of the Grimace: Criminal Mastermind or loveable fool? (imagen) A Quinn Martin Production. Confessions of a pop culture addict. Disponible en: http:// popcultureaddict.com/miscellaneous/grimace-htm/ Consultado el 6 de mayo de 2015. 
Empero, es importante aclarar que la aplicación del "observador promedio" sigue siendo subjetiva, por cuanto se basa en la percepción para probar si se configura o no infracción.

Hasta este momento se puede afirmar que de todos los anteriores test, este recoge en gran medida los criterios aplicables en otros casos y aplica la prueba de manera sistemática, realizando un examen de lo general a lo singular, con el fin de determinar la similitud a partir de los elementos verdaderamente protegidos.

\section{Propuesta para la determinación de un método DE COMPARACIÓN PARA EL CASO PARTICULAR DE LAS OBRAS CINEMATOGRÁFICAS}

Es importante indicar que la conducta de plagio afecta el ámbito interno de la obra prístina al apropiar elementos esenciales dotados de originalidad de ella, y que si bien la obra plagiaria se exterioriza como una creación aparentemente nueva y distinta de la original, esta es en todo caso carente de protección. Por lo cual, para demostrar lo anterior, es imprescindible emplear un método que permita examinar y comparar las obras en conflicto independientemente del género al que estas pertenezcan, y así revelar las similitudes sustanciales existentes con el fin de declarar la existencia de un plagio.

De esta forma, se propone un método para Colombia que permita a los jueces, en los casos particulares de plagio, comparar aquellos elementos susceptibles de protección en las obras cinematográficas, así como con otros tipos de obras, para sancionar el proceder indebido del presunto plagiador.

En el presente escrito se presenta un método para establecer la existencia de plagio que se caracteriza por:

1. La exigencia de implementar un procedimiento que permita diferenciar la idea de la expresión protegible.

2. Basarse en los aspectos fundamentales de test o pruebas empleadas en otros regímenes jurídicos, para poder delimitar los niveles de protección y excluir así los elementos carentes de tutela.

3. Estar en concordancia con los principios fundamentales del derecho de autor.

4. Ser un instrumento que permita a los operadores judiciales reconocer las similitudes esenciales en las obras que han sido apropiadas en otras de manera indebida.

5. Buscar la protección de los autores y titulares de las obras con el fin de seguir promoviendo el desarrollo de las artes.

Por lo anterior, se procede a presentar la propuesta de un método de comparación entre obras afectadas por la conducta de plagio, observando dentro del estudio una fase previa y tres etapas dentro del análisis, de la siguiente manera. 
Aspectos formales a tener en Cuenta previa la VAloración DEL PLAGIO

Como primera medida, previa la valoración de las obras en conflicto deben tenerse en cuenta seis ítems fundamentales:

1. Para demostrar la existencia del plagio debe existir una obra previa, ya sea inédita, divulgada por cualquier medio o forma, primigenia o derivada.

2. El que alega la vulneración de los derechos de autor debe ser autor o titular del producto intelectual.

3. La creación debe cumplir con el requisito de la originalidad por lo menos en algún elemento que haya sido apropiado de manera indebida.

4. Se debe demostrar por lo menos con pruebas indiciarias que el infractor pudo conocer o acceder de forma previa a la creación protegida.

5. Se debe demostrar que la conducta no se encuentra dentro de una excepción o limitación a los derechos de autor.

6. Se debe demostrar que no se está en el ámbito de la creación independiente.

Una vez verificados y cumplidos estos aspectos, se procede a realizar el estudio del plagio siguiendo tres etapas que permitirán determinar la existencia de la conducta infractora.

Primera etapa: identificación y eliminación de elementos NO SUSCEPTIBLES DE PROTECCIÓN

Esta primera fase está dirigida a identificar y delimitar el espectro de protección de la obra presuntamente afectada, estableciendo primero cuál es la naturaleza de las creaciones en conflicto, para posteriormente excluir ciertos aspectos del análisis que no están dotados del requisito esencial de la originalidad y no son objeto de tutela por el derecho de autor.

Lo anterior en razón de que el plagio puede configurarse entre obras cinematográficas, o entre una obra cinematográfica y una literaria, publicitaria, un comercial, por citar algunos ejemplos.

Posteriormente, los elementos a descartar en esta etapa son:

1. Conceptos principales y temáticas generales de las obras.

2. Personajes reales.

3. Lugares reales.

4. Hechos de la realidad.

5. Planos escenográficos (cuando hay conflicto entre obras audiovisuales).

6. Escenas naturales del género (comedia, amor, acción, aventura, terror, etc.).

Vale la pena mencionar que estos elementos son meramente enunciativos, y son escogidos como guía de esta etapa por cuanto los mismos no son suscepti- 
bles de protección y, en consecuencia, no deben entorpecer el análisis respecto de aquellos que sí se deben proteger.

Sin embargo, sobre este punto vale la pena mencionar que, si una vez se han excluido de la obra los elementos mencionados no queda ningún aspecto del que pueda predicarse el requisito de la originalidad, el examen finaliza, no se pasa a la siguiente etapa y se concluye que en el caso concreto no se configura la infracción. Empero, si aún existe expresión protegible, se continúa con la segunda etapa.

Es importante reconocer que en esta fase el proceso de distinción y exclusión de los elementos no susceptibles de protección es una tarea ardua, por lo cual es recomendable que el juez esté dotado de los conocimientos necesarios en el área del derecho de autor, pudiendo estar asistido a su vez por un perito con conocimientos especiales en la materia.

\section{Segunda etapa: valoración objetiva de las similitudes}

Esta fase se dirige a examinar los elementos literales y no literales presentes en las obras, con el fin de delimitar las semejanzas existentes y definir si son esenciales o accesorias, así como si se encuentran dotadas del requisito esencial de la originalidad para declarar la configuración del plagio.

El operador judicial en esta etapa debe analizar y tener en cuenta:

1. Guion cinematográfico: se comparan mediante su lectura y se señalan las semejanzas entre los diálogos, la selección, disposición y detalles en los contenidos.

2. Caracterización de los personajes: se compara la representación de los mismos, la fuerza en su expresión, el desarrollo y detalles, ya sean externos, como los rasgos estéticos, o internos, como los psicológicos.

3. Escenas: se comparan las secuencias y la concatenación de las mismas, por cuanto es en estas donde la similitud puede observarse de manera visual ya que relatan el desarrollo del guion.

Asimismo, deben observarse los espacios construidos y exteriorizados, también conocidos como escenografía, siempre y cuando pueda ser percibida y esté dotada del requisito esencial de la originalidad.

4. Lugares imaginarios: se compara la descripción y detalle de los lugares que surjan de la inventiva del autor o titular de la creación, con el fin de hallar semejanzas que puedan ser sustanciales y no accesorias o impuestas por el género.

5. Guion gráfico: se comparan los storyboards de ambas obras en conjunto con el guion y las escenas, con el objetivo de establecer si hay semejanzas en el desarrollo de la historia o la concatenación de secuencias.

6. Fotografía: permite comparar la escenografía, la atmósfera o ambiente, así como el juego de luz, sombras y colores empleados. Esta puede ser analizada en conjunto con las escenas y el guion gráfico. 
7. Banda sonora: en cuestiones de obras musicales debe analizarse su originalidad para proceder a comparar la letra y la melodía, mas no el ritmo.

8. El propio y personal sentido expositivo del autor: se compara la forma original en que el autor escoge, estructura y expone los contenidos y detalles para el desarrollo de la creación.

Es importante destacar que dentro del análisis de cada uno de estos ítems pueden seguirse encontrando elementos no susceptibles de protección, por lo cual esta fase sirve igualmente como un segundo filtro con vistas a depurar las coincidencias banales entre las obras.

Asimismo, en esta etapa son válidas la aplicación de cualquier medio de prueba y, en especial, la ayuda de peritos, dada la complejidad de la creación.

\section{Tercera etapa: eVAluación en CONJUnto de las Similitudes} SUSTANCIALES EXISTENTES

Una vez se han satisfecho las dos fases anteriores, el análisis se dirige a determinar si en el conjunto de elementos protegibles literales y no literales se presenta una similitud sustancial que ocasione la declaratoria del plagio.

En este sentido, el juez tiene la labor de concluir si las semejanzas existentes van más allá de las meras coincidencias, y si tal situación no se ubica dentro de una excepción o limitación en el uso de los mismos o bien se concluye que, pese a las similitudes existentes, se trata en todo caso de una creación independiente.

En consecuencia, se debe valorar la situación fáctica y legal, los medios de prueba que obren en el proceso, allegadas ya sea de oficio o a petición de parte, y los resultados del presente análisis en conjunto, atendiendo a las reglas de la sana crítica.

El anterior método es exigente, riguroso y dinámico, y se debe ir enriqueciendo con cada caso particular tratado. Los resultados obtenidos dependen del buen uso de esta herramienta de trabajo que debe ser manejada con profesionalismo y pericia, de manera de evitar su uso mecánico y facilista.

\section{Conclusiones}

Las ideas pertenecen a todo el mundo, por lo cual no es posible predicar respecto de las mismas un monopolio de apropiación, pues se generaría un desincentivo al desarrollo intelectual. En materia autoral, y específicamente en las obras cinematográficas, se presenta la problemática de delimitar o fijar su frontera para determinar cuándo y en qué casos existe protección legal. En consecuencia, la forma particular y característica por medio de la que el concepto se expresa no pertenece sino al autor, así como los elementos literales o no literales particulares que sean implementados en ella. 
La originalidad es el requisito esencial para proteger una obra. En consecuencia, para que una creación en cualquier campo, ya sea artístico o literario, merezca protección, debe manifestar o evidenciar el esfuerzo que ha realizado el autor y además debe gozar de independencia intelectual.

Por otro lado, respecto de la conducta de plagio vale la pena indicar que en la actualidad no existe un concepto unánime. Sin embargo, ya sea el plagio de tipo burdo o inteligente, se coincide en sus elementos constitutivos como la falsa atribución de la autoría y el uso no autorizado de la obra. De esta manera, el plagio puede predicarse de una reproducción total o parcial de elementos dotados del requisito esencial de la originalidad de la obra cinematográfica, derivado bien del uso de las palabras, el desarrollo, la estructuración de los conceptos o la presentación de los detalles. Asimismo, es importante mencionar que la extensión dentro de un análisis de esta conducta no es relevante, por cuanto, para que se entienda configurada la infracción, la apropiación bien puede provenir de un solo elemento sustancial.

La jurisprudencia en Colombia no ha realizado un estudio pormenorizado respecto de la conducta del plagio, encontrándose hoy día rezagada frente a otros países que están a la vanguardia en el tema; por ello, y pese a la falencia anotada, existen pocos casos que sirven de referente y permiten sentar jurisprudencia y doctrina al respecto. Pese a ello, por el momento estas falencias pueden ser suplidas con la ayuda de legislaciones extranjeras, particularmente de Estados Unidos, Argentina y España.

El criterio o estándar de la similitud sustancial es frecuentemente empleado tanto por la jurisprudencia nacional como por la extranjera, con el objeto de determinar la configuración del plagio en aquellos eventos en que se produce o se realiza una copia respecto de los elementos estructurales, básicos y fundamentales de una obra cinematográfica ajena dotada del requisito esencial de la originalidad. En consecuencia, este criterio deviene en herramienta fundamental para detectar y evidenciar las argucias empleadas por el plagiador para disimular u ocultar la indebida apropiación con el fin de que la infracción no sea detectada y se pueda hacer aparecer como propio lo que en realidad nunca lo ha sido.

La detección del plagio mediante el criterio de la similitud sustancial no recae sobre los elementos disímiles que aparezcan entre las creaciones, por cuanto en este último escenario mal podría darse el estudio de elementos no susceptibles de protección, y a la vez se ocasionaría que el actuar del plagiador no se sancionara. Si bien es cierto este criterio resulta disímil en el sistema de common law y en el de civil law, su uso en la práctica deviene en uno y otro régimen en herramienta clave y fundamental para determinar la efectiva apropiación de elementos literales o no literales revestidos de originalidad y que son incorporados sin autorización en otra obra. 
Así, si bien en la praxis resulta difícil definir la frontera entre las ideas y su expresión, la determinación de los elementos dotados del requisito esencial de la originalidad en una obra cinematográfica es una labor propia del operador judicial, asistido o no por un auxiliar de justicia, teniendo en cuenta que el estudio debe realizarse de manera particular para así precisar cuándo se configura el plagio, cualquiera que sea su modalidad. De esta manera, el análisis de la conducta se realiza en cada caso particular atendiendo a la importancia de las coincidencias a nivel cualitativo, teniendo en cuenta además que esta no se limita a productos intelectuales de géneros iguales sino que comprende también los de géneros diferentes, por lo cual deben prevalecer en cualquier evento las semejanzas y no las diferencias.

Este trabajo propone un método que permite determinar el plagio, en particular, de las obras cinematográficas, a partir del contexto descrito a lo largo del documento, siendo el aporte fundamental del autor del presente. Este método consta de una fase previa y tres etapas subsiguiente, con sus correspondientes ítems de trabajo. En la fase previa, a las obras en conflicto se les aplican seis aspectos básicos a modo enunciativo, antes de pasar a la primera etapa, en la cual se identifica y delimita el espectro de protección de la obra presuntamente afectada; en la segunda etapa se hace una valoración objetiva de las similitudes (elementos literales y no literales), siendo importante resaltar la calidad de las pruebas y, en muchos casos, la ayuda de un experto para los temas especializados; y finalmente, en la tercera etapa se hace una evaluación de las similitudes sustanciales existentes. Esta metodología de trabajo, sin duda, ayuda al juez del caso en la determinación de la existencia o no del plagio y, eventualmente, en la aplicación de las sanciones a que haya lugar.

Asimismo, esta propuesta es una herramienta de trabajo que se debe ir enriqueciendo con cada caso tratado, y su éxito depende de la pericia y conocimiento de quien la aplique. Exige profesionalismo, rigurosidad conceptual y procedimental en su aplicación, para así evitar un uso mecanicista que pueda conducir a una rutina con consecuencias desastrosas.

En consecuencia, para la detección efectiva del plagio es importante proponer, adoptar y aplicar un método sistemático estructurado a través de diversos pasos con el fin de depurar los elementos carentes de protección, para así encontrar el núcleo fundamental de la creación cinematográfica afectada respecto de los elementos artísticos, y no sobre los técnicos o de carácter industrial, ya que en relación con estos últimos no se entiende que se dé un desarrollo del intelecto.

\section{Bibliografía}

Abie's Irish Rose. (Imagen). Meridian Gallery-Art \& Design, Truth, Beauty and the power of Ornamentation. Disponible en: http://meridiangallery.blogspot. com/2014/06/nancy-carroll-1903-1965-what-sweetie.html 
Algardi, Zara Olivia. La tutela dell'opera dell ingegno e il plagio. Padova, Cedam, 1978.

Antequera Parilli, Ricardo. Derechos Intelectuales y Derecho a la Imagen en la Jurisprudencia Comparada. Colección de Propiedad Intelectual. Madrid, Reus. 2012.

Antequera Parilli, Ricardo. Daño moral. Apreciación. Paternidad. Plagio. Argentina. Cámara Nacional de Apelaciones en lo civil, Sala F. 14 de octubre de 1991. Jurisdicción Judicial (civil). Texto del fallo en "La Ley" (1992-B), 475-479. P., Daniel H. vs. Editorial A., S.A.

Antequera Parilli, Ricardo. Daño moral. Apreciación. Paternidad. Plagio. Colombia. Tribunal Superior del Distrito Judicial de Cali. 12 de marzo de 1993. Jurisdicción Judicial (civil). Texto del fallo en copia original. Recurso de apelación contra decisión del Juzgado 8. ${ }^{\circ}$ Civil de Cali.

Antequera Parilli, Ricardo. Daño moral. Elementos para su apreciación. Plagio. Extensión del plagio. Brasil. Novena Cámara Civil del Tribunal de Justicia del Estado de Rio Grande Do Sul. 10 de agosto de 2011. Jurisdicción Judicial Civil. Texto del fallo disponible en el portal del Tribunal de Justicia del Estado de Rio Grande Do Sul: http://www.tjrs.jus.br. Traducción Ricardo Antequera Parilli. Apelación civil 7004382717.

Antequera Parilli, Ricardo. El registro. Efectos. Omisión. Irrelevancia en caso de plagio. Argentina. Cámara Nacional de Apelaciones en lo Civil, Sala E. 20 de octubre de 2005. Jurisdicción Judicial Civil. Biblioteca Jurídica Online, disponible en: http://www.eldial.com.ar/ Referencia AA303C. Causa 430819. ARCE, Rodolfo Adrían vs. suar, Adrián y otros.

Antequera Parilli, Ricardo. Daño moral. Apreciación. Paternidad. Plagio. Argentina. Cámara Nacional de Apelaciones en lo civil, Sala F. 14 de octubre de 1991. Jurisdicción Judicial (civil). Texto del fallo en "La Ley" (1992-B), 475-479. P., Daniel H. vs. Editorial A., S.A.

Antequera Parilli, Ricardo. Daño moral. Apreciación. Paternidad. Plagio. Colombia. Tribunal Superior del Distrito Judicial de Cali. 12 de marzo de 1993. Jurisdicción Judicial (civil). Texto del fallo en copia original. Recurso de apelación contra decisión del Juzgado 8. ${ }^{\circ}$ Civil de Cali.

Antequera Parilli, Ricardo. Daño moral. Elementos para su apreciación. Plagio. Extensión del plagio. Brasil. Novena Cámara Civil del Tribunal de Justicia del Estado de Rio Grande Do Sul. 10 de agosto de 2011. Jurisdicción Judicial Civil. Texto del fallo disponible en el portal del Tribunal de Justicia del Estado de Rio Grande Do Sul: http://www.tjrs.jus.br. Traducción Ricardo Antequera Parilli. Apelación civil 7004382717.

Antequera Parilli, Ricardo. El registro. Efectos. Omisión. Irrelevancia en caso de plagio. Argentina. Cámara Nacional de Apelaciones en lo Civil, Sala E. 20 de octubre de 2005. Jurisdicción Judicial Civil. Biblioteca Jurídica Online, 
disponible en: http://www.eldial.com.ar/ Referencia AA303C. Causa 430819. ARCE, Rodolfo Adrían vs. suar, Adrián y otros.

Antequera Parilli, Ricardo. Objeto del derecho. Forma de expresión. Uso de las ideas. Obra científica. Argentina. Cámara Nacional de Apelaciones en lo Civil, Sala A. Octubre de 2006. Jurisdicción Judicial (Civil). Biblioteca Jurídica Online, disponible en: http://www.eldial.com/ Referencia AA39B. Giangreco, Luis vs. Editorial Errepar S.A.

Antequera Parilli, Ricardo. Plagio. Apreciación. Programa de televisión. Formato. Uso de elementos comunes. Rechazo. Argentina. Cámara Nacional de Apelaciones en lo Civil, Sala D. 12 de febrero de 2009. Jurisdicción Judicial (civil). Texto del fallo en formato digital. Paz, Teodosio Luis vs. Asociación Argentina de Televisión por Cable A.T.V.C.

Antequera Parilli, Ricardo. Plagio. Apreciación de las semejanzas. Obra Didáctica. España. Audiencia Provincial de Almería, Sección 3. ${ }^{\text {a }} 10$ de junio de 2004. Jurisdicción Judicial (civil). Texto del fallo disponible en el portal del Consejo General del Poder Judicial de España: http://www.poderjudicial.es/ jurisprudencia, Sentencia 141/04.

Antequera Parilli, Ricardo. Plagio. Apreciación de las semejanzas. "Software”. Chile. Corte Suprema de Justicia. 15 de septiembre de 1999. Jurisdicción Judicial. Texto del fallo en copia del original. Sfeir y otros vs. Universidad de Concepción.

Antequera Parilli, Ricardo. Plagio. Apreciación en concreto. Idea y forma de expresión. Elementos intrínsecos y extrínsecos. Muñecas. Estados Unidos de América. Corte de Apelaciones para el 9. ${ }^{\circ}$ Circuito. 22 de julio de 2010. Jurisdicción Judicial (Civil). Disponible en: http://www.ca9.uscourts.gov/. Traducción Espinal, Melisa. Rnb. Mattel, Inc., y otros vs. MGa Entertainment, Inc. y otros. n. ${ }^{\circ}$ 09-55812. D.C. No. 2:04-cv-09049-sGL.

Antequera Parilli, Ricardo. Plagio. Apreciación en concreto. Rechazo. Creación Independiente. Idea y forma de expresión. Pintura. Parque temático. Estados Unidos de América. Tribunal de Apelaciones para el $11^{\circ}$ circuito. 2 de noviembre de 2006. Jurisdicción Judicial Civil. Disponible en: http://www. ca11.uscourts.gov. Traducción Melisa Espinal. 02-01377-cv-ORL-19Krs. Orrin Monroe Corwin vs. Walt Disney Company.

Antequera Parilli, Ricardo. Plagio. Marco conceptual, apreciación en concreto. Derechos infringidos. Perú. Sala de Propiedad Intelectual del Tribunal de INDECopr. 29 de mayo de 2008. Jurisdicción Administrativa. Texto digitalizado de la Resolución, cortesía de InDECopi. Resolución 1266-2008/TPI-INDECopI. Antequera Parilli, Ricardo. Plagio. Marco conceptual. Argentina. Cámara Nacional de Apelaciones en lo Civil, Sala G. 21 de marzo de 1994. Jurisdicción Judicial (civil). Texto del fallo en "Jurisprudencia Argentina" (1994-Iv), 410. M. Venancio vs. Julio y otros. 
Antequera Parilli, Ricardo. Plagio. Marco conceptual. Plagio de coautor. Obra en colaboración. Perú. Tribunal de Defensa de la Competencia y de la Propiedad Intelectual de indecopi. Sala de Propiedad Intelectual. 1 de junio de 2009. Jurisdicción Administrativa. Texto digitalizado de la Resolución, cortesía INDECOPI. Resolución 1382-2009/TPI-INDECOPI.

Antequera Parilli, Ricardo. Plagio. Marco conceptual. Plagio simulado. España. Audiencia Provincial de Madrid, Sección 11 a 6 de junio de 2007. Jurisdicción Judicial (civil). Disponible en el portal del Consejo General del Poder Judicial de España: http://www.poderjudicial.es/jurisprudencia, Sentencia 455/2007.

Antequera Parilli, Ricardo. Plagio. Piratería. Diferencias. Perú. Oficina de Derecho de Autor del indecopi. 13 de marzo de 2007. Jurisdicción Administrativa. Cita de la Resolución 1808-2007/TPI-INDECOPI. Resolución 862007/ODA-INDECOPI.

Antequera Parilli, Ricardo. Pruebas. Dictamen pericial. Apreciación. Obra audiovisual. Guion. Argentina. Cámara Nacional de Apelaciones en lo Civil, Sala I. 5 de agosto de 1999. Jurisdicción Judicial (civil). Texto del fallo en formato papel. Guebel, Norberto vs. Fernández Musiak, Diego.

Antequera Parilli, Ricardo. Objeto del derecho. Forma de expresión. Uso de las ideas. Obra científica. Argentina. Cámara Nacional de Apelaciones en lo Civil, Sala A. Octubre de 2006. Jurisdicción Judicial (Civil). Biblioteca Jurídica Online, en: http://www.eldial.com/ Referencia AA39B. Giangreco, Luis vs. Editorial Errepar S.A.

Antequera Parilli, Ricardo. Plagio. Apreciación. Programa de televisión. Formato. Uso de elementos comunes. Rechazo. Argentina. Cámara Nacional de Apelaciones en lo Civil, Sala D. 12 de febrero de 2009. Jurisdicción Judicial (civil). Texto del fallo en formato digital. Paz, Teodosio Luis vs. Asociación Argentina de Televisión por Cable A.T.V.C.

Antequera Parilli, Ricardo. Plagio. Apreciación de las semejanzas. Obra Didáctica. España. Audiencia Provincial de Almería, Sección 3. a 10 de junio de 2004. Jurisdicción Judicial (civil). Disponible en el portal del Consejo General del Poder Judicial de España: http://www.poderjudicial.es/jurisprudencia, Sentencia 141/04.

Antequera Parilli, Ricardo. Plagio. Apreciación de las semejanzas. "Software". Chile. Corte Suprema de Justicia. 15 de septiembre de 1999. Jurisdicción Judicial. Texto del fallo en copia del original. Sfeir y otros vs. Universidad de Concepción.

Antequera Parilli, Ricardo. Plagio. Apreciación en concreto. Idea y forma de expresión. Elementos intrínsecos y extrínsecos. Muñecas. Estados Unidos de América. Corte de Apelaciones para el 9. ${ }^{\circ}$ Circuito. 22 de julio de 2010. Jurisdicción Judicial (Civil). Texto del fallo en http://www.ca9.uscourts.gov/. 
Traducción Espinal, MeLisa. Rnb. Mattel, Inc., y otros vs. MGa Entertainment, Inc. y otros. N. ${ }^{o}$ 09-55812. D.C. n. ${ }^{\circ}$ 2:04-cv-09049-sGL.

Antequera Parilli, Ricardo. Plagio. Apreciación en concreto. Rechazo. Creación Independiente. Idea y forma de expresión. Pintura. Parque temático. Estados Unidos de América. Tribunal de Apelaciones para el 11. ${ }^{\circ}$ Circuito. 2 de noviembre de 2006. Jurisdicción Judicial Civil. Disponible en: http:// www.ca11.uscourts.gov Traducción Melisa Espinal. 02-01377-CV-ORL-19KRS. Orrin Monroe Corwin vs. Walt Disney Company.

Antequera Parilli, Ricardo. Plagio. Marco conceptual, apreciación en concreto. Derechos infringidos. Perú. Sala de Propiedad Intelectual del Tribunal de INDECOPI. 29 de mayo de 2008. Jurisdicción Administrativa. Texto digitalizado de la Resolución, cortesía de INDECOPI. Resolución 1266-2008/TPI-INDECOPI. Antequera Parilli, Ricardo. Plagio. Marco conceptual. Argentina. Cámara Nacional de Apelaciones en lo Civil, Sala G. 21 de marzo de 1994. Jurisdicción Judicial (civil). Texto del fallo en "Jurisprudencia Argentina" (1994-Iv), 410. M. Venancio vs. Julio y otros.

Antequera Parilli, Ricardo. Plagio. Marco conceptual. Plagio de coautor. Obra en colaboración. Perú. Tribunal de Defensa de la Competencia y de la Propiedad Intelectual de InDecopi. Sala de Propiedad Intelectual. 1 de junio de 2009. Jurisdicción Administrativa. Texto digitalizado de la Resolución, cortesía de INDECOPI. Resolución 1382-2009/TPI-INDECOPI.

Antequera Parilli, Ricardo. Plagio. Marco conceptual. Plagio simulado. España. Audiencia Provincial de Madrid, Sección 11a. 6 de junio de 2007. Jurisdicción Judicial (civil). Disponible en el portal del Consejo General del Poder Judicial de España: http://www.poderjudicial.es/jurisprudencia Sentencia 455/2007.

Antequera Parilli, Ricardo. Plagio. Piratería. Diferencias. Perú. Oficina de Derecho de Autor del indecopi. 13 de marzo de 2007. Jurisdicción Administrativa. Cita de la Resolución 1808-2007/TPI-INDECopi. Resolución 862007/ODA-INDECOPI.

Antequera Parilli, Ricardo. Pruebas. Dictamen pericial. Apreciación. Obra audiovisual. Guion. Argentina. Cámara Nacional de Apelaciones en lo Civil, Sala I. 5 de agosto de 1999. Jurisdicción Judicial (civil). Texto del fallo en formato papel. Guebel, Norberto vs. Fernández Musiak, Diego.

Balbuena, Pedro Virgilio. "El plagio como ilícito penal", en Revista Ventana Legal. Disponible en: http://www.ventanalegal.com/revista_ventanalegal/ plagio_ilicito.htm\#_ftn8

Boston College Law School. Intellectual Property. Copyright-Ownership, Duration. January 18, 2008. Disponible en: https://www2.bc.edu/ liujr/courses/ ip08s/powerpoint/c05-c-ownership.ppt 
Boyta, Gyorgy. Glosario de derecho de autor y derechos conexos. Ginebra, OMPI, 1980.

Castellanos, Carlos. "Ajustes iusteóricos y metodológicos acerca de la dicotomía idea/expresión: las aproximaciones y desarrollos jurisprudenciales que las Cortes norteamericanas han experimentado en el entendimiento y análisis de la dicotomía idea/expresión", Revista Iberoamericana de Derecho de Autor: Estudios, Jurisprudencia. Centro Regional para el Fomento del Libro en América Latina y El Caribe, CERlalc, año v, n. ${ }^{\circ}$ 10, julio-diciembre, 2011. Código de los Estados Unidos de América. Título 15, Ley de Marcas. United States Code Title $15 \$ 1125$ y Título 17, Ley de Copyright. United States Code Title $17 \$ 10,13$ and 209. Disponible en: (http://www.bitlaw.com/ source/15usc/1125.html

Convenio Antipiratería para Colombia. "Derecho de autor y derechos conexos en Colombia. Aspectos jurídicos”, en Herrera Osorio, Fredy Andrei (comp.), 2. ${ }^{a}$ ed., Bogotá, Panamericana Formas e Impresos, 2008.

Convenio de Berna para la Protección de las Obras Literarias y Artísticas, 1886. Convención Universal sobre Derecho de Autor, 1971.

Copyright Infringement II, Intro to IP - Prof Merges. 2.23.09. Berkeley Law. Disponible en: https://www.law.berkeley.edu/files/17._-_2.23.09_-_Copyright_Infringement_II.ppt

Cordy Castañeda, Alberto, López Cubillos, Rafael, López Sarmiento, Armando y Gordillo Vallecilla, Jaime. La contribución económica de las industrias del Derecho de Autor y los Derechos Conexos en Colombia. Bogotá, OMPI, 2008. Disponible en: http://derechodeautor.gov.co/documents/10181/46348/ Estudio+Ompi+Colombia.pdf/27f06d22-7c6b-461c-919d-9859cfddb930

Corte de Apelaciones del Segundo Circuito de Estados Unidos. Nichols v. Universal Pictures Corporation. (2nd Cir.) (1930). 45 F.2d 119. Judge L. Hand. Disponible en: http://digital-law-online.info/cases/7pq84.htm y http://law. justia.com/cases/federal/district-courts/F2/34/145/1481990/

Corte de Apelaciones del Séptimo Circuito de Estados Unidos. Selle v. Gibb 741 f. 2 d 896 (7th Cir. 1984) Judge Cudahy. Disponible en: http://mcir.usc.edu/ cases/1980-1989/Pages/sellegibb.html

Corte de Apelaciones del Noveno Circuito de Estados Unidos. Roth Greeting Cards V. United Card Company. (9th Cir.) (1970). 429 F.2d 1106 Judge. Hamley. Disponible en: http://scholar.google.ca/scholar_case? case $=4616368592376$ 161797\&hl=en\&as_sdt=2\&as_vis=1\&oi=scholarr\&sa=X\&ei=NAvnT6f1 F qnM2AX66IzaCQ\&ved=0CBgQgAMoADAA

Corte de Apelaciones del Noveno Circuito de Estados Unidos. Sid \& Marty Krofft Television Productions, Inc. v. McDonald's Corporation And Needham, Harper \& Steers, Inc. (9th Cir.) (1977) 562 F. 2d 1157196 U.S.P.Q. 97 Judge Carter. Disponible en: https://law.resource.org/pub/us/case/reporter/ 
F2/562/562.F2d.1157.75-1202.75-1203.html http://law.justia.com/cases/ federal/appellate-courts/F2/562/1157/293262/ http://www.studentweb.law. ttu.edu/Cochran/Cases\%20\&\%20Readings/Copyright-UNT/krofft.htm

Decisión 351 de 1993 de la Comunidad Andina de Naciones.

Decisión 486 de 2000 de la Comunidad Andina de Naciones.

Declaración Universal de Derechos Humanos, 1948.

Della Costa, Héctor. El derecho de autor y su novedad. Estructura-dinámicaproblemática. 2. a ed. Buenos Aires, Editorial de Belgrano, 1970.

González Gómez, Alejandro. El tipo básico de los delitos contra la propiedad intelectual. Madrid, Tecnos, 1998.

Gutiérrez, Angélica. "El plagio literario", en Quadernos de criminología: Revista de criminología y ciencias forenses (2010), n. ${ }^{\circ} 10$.

Krofft v. McDonald's-9th Cir 1977-Copyright in Hamburgler and Mayor McCheese. Substantial Similarity. July 9, 2013. Disponible en: http://www. copyrightcodex.com/tag/substantial-similarity

Law School Case Briefs. Nichols v. Universal Pictures Corp. (2nd Cir.) (1930). 45

F.2d 119. Disponible en: http://www.invispress.com/law/property/nichols.html

Law School Case Briefs. Roth Greeting Cards v. United Card Co. 429 F.2d 1106 (9th Cir. 1970). Disponible en: http://www.invispress.com/law/copyright/ roth.html

Law School Case Briefs. Sid \& Marty Krofft Television Productions, Inc. v. McDonald's Corporation And Needham, Harper \& Steers, Inc. 562 F. 2d 1157 (9th Cir. 1977). Disponible en: http://www.invispress.com/law/copyright $/$ krofft.html

Ley 23 de 1982 sobre derechos de autor.

Ley 599 de 2000, por la cual se expide el Código Penal.

Ley 1564 de 2012, por medio de la cual se expide el Código General del Proceso y se dictan otras disposiciones.

Lipszyc, Delia. Derecho de autor y derechos conexos. Buenos Aires, unesco/cerLALC/ZAVALIA, 1993.

Ministerio de Cultura. Impacto económico de las industrias culturales en Colombia. Bogotá, Ministerio de Cultura de Colombia, Equipo Central de Economía y Cultura del Convenio Andrés Bello. 2003. Disponible en: http://www.odai. org/biblioteca/biblioteca1/4.pdf

Monroy Rodríguez, Juan Carlos. Derecho de autor y derechos conexos. Legislación, doctrina y jurisprudencia concordada y comentada. Bogotá, RRA Formación, 2013.

Organización de las Naciones Unidas para la Educación, la Ciencia y la Cultura, unEsco. El ABC del derecho de autor. Mayenne, Imprimerie de la Manutention, 1981. 
Organización Mundial de Comercio. Acuerdo sobre los Aspectos de los Derechos de Propiedad Intelectual relacionados con el Comercio (ADPIC) o (TRIPs). (Ronda de Uruguay, 1994).

Osterberg, Robert C. y Osterberg, Eric C. Substantial Similarity in Copyright Law. New York, United States of America: PLI-Practicing Law Institute. 2014. Disponible en: http://www.pli.edu/public/booksamples/631_sample3.pdf

Parra Quijano, Jairo. Manual de Derecho Probatorio. La prueba en los procedimientos: civil, penal (ordinario y militar), laboral, canónico, contenciosoadministrativo y en el derecho comparado. 16. a ed., Bogotá, Librería Ediciones del Profesional, 2007.

Rengifo García, ERnesto. “ ¿Es el plagio una conducta reprimida por el derecho penal?", en Revista de la Propiedad Inmaterial (2010), n. ${ }^{\circ} 14$.

Sentencia 31403 de 28 de mayo de 2010. M.P.: Sigifredo Espinosa Pérez.

Sentencia STs 28 de enero de 1995. Disponible en: http://supremo.vlex.es/vid/ honorarios-intelectual-plagio-proyecto-ba-ma-17741522

Sentencia STs 17 de octubre de 1997. Disponible en: http://www.uclm.es/profesorado/jjmarin/tema_2.doc

Sentencia STs 23 de marzo de 1999. Disponible en: http://www.poderjudicial. es/search/

Sentencia sTs 27 de enero de 2001. Disponible en: http://www.poderjudicial. es/search/

Sentencia sTs 23 de octubre de 2001. Disponible en: http://www.poderjudicial. es/search/

Sentencia ssTs 26 de noviembre de 2003. Disponible en: http://www.poderjudicial.es/search/

Sid \& Marty Krofft Television Productions, Inc. v. McDonald's Corp. (9th Cir. 1977). 562 F.2d 1157. Copyright in a Global Information Economy, Chapter 5. Disponible en: http://www.coolcopyright.com/cases/chp5/ kroftmcdonalds.htm

The evolution of the Grimace: Criminal Mastermind or loveable fool? (Imagen) A Quinn Martin Production. Confessions of a pop culture addict. Disponible en: http://popcultureaddict.com/miscellaneous/grimace-htm/

The Cohens \& Kelly's. (Imagen). Copyright in a Global Information Economy, Chapter 5. Disponible en: http://www.coolcopyright.com/cases/chp5/nicholsuniversal.htm

Tobón Franco, Natalia y Varela Pezzano, Eduardo. Derecho de autor para creativos. Bogotá, Grupo Editorial Ibáñez, 2010.

Tratado de la Organización Mundial de la Propiedad Intelectual sobre Derecho de Autor (wCT), 1996.

Tratado sobre el Registro Internacional de Obras Audiovisuales, 1989. 
Tribunal de Justicia de la Comunidad Andina. Proceso 10-IP-99. Lexis S.A. vs. la empresa Productora e Información Compañía Ilimitada (prodinfo). Quito, Ecuador. 11 de junio de 1999. Disponible en: http://view.officeapps. live.com/op/view.aspx?src=http\%3A\%2F\%2Fintranet.comunidadandina. org\%2FDocumentos\%2FProcesos\%2F10-ip-99.doc

Tribunal de Justicia de la Comunidad Andina. Proceso 139-Ip-2003. Solicitud de interpretación prejudicial de los artículos 1, 4 literal a), 8, 11 literales a), b), c), 52, 54, 55 de la Decisión 351 de la Comisión del Acuerdo de Cartagena. Quito, Ecuador. 7 de marzo de 2004. Disponible en: http://view.officeapps. live.com/op/view.aspx?src=http\%3A\%2F\%2Fintranet.comunidadandina.or g\%2FDocumentos\%2FProcesos\%2F139-ip-2003.doc 